\title{
Eight emitters clogging characteristics and its suitability under on-site reclaimed water drip irrigation
}

\author{
Yiting Pei $\cdot$ Yunkai Li $\cdot$ Yaoze Liu \\ Bo Zhou $\cdot$ Ze Shi $\cdot$ Yinguang Jiang
}

Received: 18 July 2012/ Accepted: 21 October 2013/Published online: 12 November 2013

(C) Springer-Verlag Berlin Heidelberg 2013

\begin{abstract}
Drip irrigation is the most effective and reliable method for reclaimed water irrigation. The water usually contains a lot of suspended particles, metal salt ions, organisms and microbial communities, which will enhance the possibility of emitter clogging or more complex clogging mechanism. Emitter clogging has become one of the key problems to the application and popularization of the drip irrigation technology. In this paper, we selected four kinds of pressure-compensating emitters and four kinds of non-pressure-compensating emitters, and executed the experiment of drip irrigation with on-site reclaimed water treated with cyclic activated sludge system (CASS). The emitter discharge ratio variation (Dra), coefficient of uniformity $(\mathrm{CU})$ and clogging rate distribution were analyzed to evaluate the emitter clogging characteristics after eliminating the effect of temperature and pressure on the emitter outflow by data correction. The results showed that Dra and CU varied in three periods as system operation. The beginning of experiment was the fluctuated balance period, Dra and CU recurrent fluctuated in $5 \%$, and the emitters clogged at some spots after the system run
\end{abstract}

Communicated by K. Stone.

Y. Pei · Y. Li $(\bowtie) \cdot$ Y. Liu $\cdot$ B. Zhou $\cdot$ Z. Shi

College of Water Resources and Civil Engineering, China

Agricultural University, Beijing 100083, China

e-mail: liyunkai@126.com

Y. Li

State Key Laboratory of Urban and Regional Ecology, Research Center for Eco-Environmental Sciences, Chinese Academy of Sciences, Beijing 100085, China

Y. Jiang

Beiqijia Sewage Treatment Plant, CPWAB, Beijing 102209, China
36-48 h. Then the two parameters varied linearly in 60-108 h, tuning into the initiate linear period, as the nonpressure-compensating emitters got an obvious linear change than the pressure-compensating ones with the gradient changed from -0.094 to 0.042 and -0.073 to 0.047 , respectively. Some of the emitters have a significant difference on these two parameters at this stage. After the restarting in the second year, Dra and CU decreased sharply. The maximum decrement was, respectively, 9.6 and $10.7 \%$. Then they varied in line with a greater slope degree as all emitters reached the significant level, the gradient ranges were -0.176 to 0.115 and -0.216 to 0.117 , respectively. This stage was called the accelerated linear period. Seriously clogged and completely clogged emitters appeared, and both Dra and CU dropped down to 38.7 and $41.5 \%$. Various degrees of clogged emitters often emerged in the end part of lateral at first then propelled to the head gradually, the completely clogged emitters in the end accounted for more than $73.0 \%$ when the system run $540 \mathrm{~h}$. Comprehensively considered, the pressure-compensating emitters and cusp-shaped saw-tooth non-pressure-compensating emitters with short flow path are recommended in reclaimed water drip irrigation. These researches are aimed to provide references explaining the emitter clogging mechanism of reclaimed water drip irrigation as well as its technological application and popularization.

\section{Introduction}

Using the sewage with proper technique treated is an effective approach to solve water shortage in arid and semiarid areas. The reclaimed water has become a stable, reliable and economical water source (Asano et al. 2007). However, wastewater still contains more substances than clean water. 
The soil, plant and underground water, as well as human health, would both face a bigger risk when the sewage is excessive. The drip irrigation is the most secure and reliable pattern for reclaimed water usage, which irrigates the soil around plant roots directly with a series of low pressure pipes and emitters, fine and controllably (World Health Organization 2006; Scott et al. 2004; Duran-Ros et al. 2009; Nakayama and Bucks 1991). The emitter is one of the key components in drip irrigation system. However, due to narrow flow path of $0.5-1.2 \mathrm{~mm}$, it can be easily clogged by pollutants like suspended particles, chemical deposits and microorganism, which may eventually destroy the whole system ( $\mathrm{Li}$ et al. 2006). Thus, it is urgent to study the mechanism of emitter clogging in the reclaimed water drip irrigation and the control model, as it is one of the key and difficult points of improving reclaimed water drip irrigation technique. The study is certified with important theoretical significance and practical value.

Almost all the previous researches showed that water quality was the main and immediate cause of emitter clogging. Bucks (1979) analyzed the emitter clogging factor in detail and suggested a water quality classification method of emitter clogging, which is supported by most experts (Bucks et al. 1979). Nakayama and Bucks (1991) summarized the research progress systematically and put forward a water quality grading standard of causing emitter clogging, which regarded the suspended particles, salinity and $\mathrm{pH}$ as the sensitive factor of emitter clogging (Nakayama and Bucks 1991). Reclaimed water has a complex quality, which contains a lot of suspended particles, salt irons, algae, organic pollutant and microorganism. Those particles would make a series of physical, chemical and microbial dynamics behaviors with other materials, making emitter clogging easier in reclaimed water drip irrigation, leaving a much more complicated mechanism (Duran-Ros et al. 2009; Adin and Sacks 1991; Ravina et al. 1992).

Researchers home and aboard had studied on reclaimed water drip irrigation already. Capra and Scicolone (2004) studied emitters and filters of drip irrigation using wastewater in south Italy and suggested that water quality, like suspended particles and organics, had a significant impact on the parameters which reflecting emitter clogging (Capra and Scicolone 2004). Puig-Bargues et al. (2010) tested emitters with wastewater for $540 \mathrm{~h}$ and found there were a minor physical clogging hazard, but moderated chemical and biological clogging hazards (Puig-Bargues et al. 2010). Gilbert et al. (1981) researched on emitter structure and water quality and found that flow path structure is another main factor on emitter clogging degree (Gilbert et al. 1981). Adin and Sacks (1991) observed that emitters with long or complicated flow path were more likely to clog, while pressure-compensating emitters with short flow path clogged less (Adin and Sacks 1991). Wu et al. (2008) pointed out there was a positive relationship between emitter outflow falling range and crosssectional area of flow path, and emitters with the function of self-cleaning, short flow path or small cross-sectional area may be suitable in reclaimed water drip irrigation (Wu et al. 2008). Liu and Huang (2009) noted that the discharged and coefficient of uniformity of turbulent emitters, laminar flow and pressure-compensating emitters with labyrinth flow path were much smaller than those using clean water, among which the pressure-compensating emitters worked best and the laminar flow emitters clogged seriously, in reclaimed water drip irrigation (Liu and Huang 2009). Duran-Ros et al. (2009) studied the emitters clogging variation under different filters, and discharge of most emitters was above $83 \%$ after irrigated $525 \mathrm{~h}$ (Duran-Ros et al. 2009). Li et al. (2009) studied 6 types of emitters using reclaimed water and underground water, finding out that outflow of reclaimed water emitters reduced 10-98\%, coefficient of uniformity ranged from 3 to $65 \%$ and most emitters clogged worse with reclaimed water (Li et al. 2009 ). Puig-Bargues et al. (2005) indicated that emitter outflow ranged from 0 to $92 \%$ when three different emitters' test finished after $750 \mathrm{~h}$ (Puig-Bargues et al. 2005). Yan et al. (2010) studied reclaimed water drip irrigation emitters for $360 \mathrm{~h}$ and found that different emitters reduced $14.4-72.2 \%$ and the emitter that had the longest flow path decreased the most.

Overall, most related researches were limited in the laboratory (Ravina et al. 1997; Capra and Scicolone 2004; Liu and Huang 2009; Wu et al. 2008; Li et al. 2005, 2009, 2012a; Yan et al. 2011). Although these tests were precise and eliminate the effect of environment, the water quality may vary during transporting, differentiating the real working condition of emitters. The evaluation method of emitter clogging needs improvement. If the flow deviation caused by temperature and actual work pressure changing is not wiped off, the measured outflow could not reflect the veritable emitters clogging situation. Furthermore, the testing time was short in most experiments (Liu and Huang 2009; Li et al. 2009; Wu et al. 2008). Experiments rarely restarted in the second year, so it was hard to reflect the long-term working status of emitters. There were also obvious differences between different typeset of emitters (Taylor et al. 1995; Gilbert et al. 1981), that is why evaluation of the suitability of different emitters was urgently required.

Based on these, we selected four pressure-compensating and four non-pressure-compensating emitters commonly used in China and executed the experiment of drip irrigation with on-site reclaimed water treated with cyclic activated sludge system (CASS). The emitter outflow correcting method was established for eliminating the effect of temperature and pressure. After this, the emitter clogging characteristics in two-year operation were analyzed from the emitter relative average discharge, $\mathrm{CU}$ and clogging rate distribution. 
The objectives of this work were as follows: (1) to work out the suitability of 8 emitters on CASS reclaimed water drip irrigation; (2) to find the clogging mechanisms of drip irrigation emitters using reclaimed water; and (3) to recommend suitable emitter types for irrigation with reclaimed water treated with CASS.

\section{Materials and methods}

Water qualities

The experiment was set and performed in the Beiqijia sewage treatment plant, Beijing, China. Wastewater was treated with CASS in this plant, which was developed based on the SBR (sequencing batch reactor activated sludge process). The experiment was using the secondary effluent in the contact disinfection pools treated every day. The water reclamation technological process is shown in Fig. 1.

During the experiment, data of water quality characteristics are daily recorded by an online water quality monitoring system, which is set around the water outlet in the plant. The monitoring system contains water quality automatic measuring instruments, automatic samplers, and a monitoring system, monitoring contents included COD (Chemical Oxygen Demand), SS (Suspended Solid), $\mathrm{NH}_{4}{ }^{+}$$\mathrm{N}$ (Ammonium Nitrogen), TP (Total Phosphorus), $\mathrm{pH}$ and temperature in the certain time every day. The information of relative instruments is listed in Table 1 . Water quality data are displayed in Fig. 2. The COD varied around $17.39 \mathrm{mg} / \mathrm{L}$, with a maximum of $40.8 \mathrm{mg} / \mathrm{L}$ and a minimum of $1.2 \mathrm{mg} / \mathrm{L}$. SS varied around $7.70 \mathrm{mg} / \mathrm{L}$, the maximum was $42.9 \mathrm{mg} / \mathrm{L}$ and minimum was $0.3 \mathrm{mg} / \mathrm{L} . \mathrm{NH}_{4}{ }^{+}-\mathrm{N}$ changed between 12.1 and $0.136 \mathrm{mg} / \mathrm{L}$, and the average value was $2.72 \mathrm{mg} / \mathrm{L}$. TP was fluctuated around $0.80 \mathrm{mg} / \mathrm{L}$, with maximum $3.4 \mathrm{mg} / \mathrm{L}$ and minimum $0.135 \mathrm{mg} / \mathrm{L}$. $\mathrm{pH}$ was fluctuated slightly between 7.52 and 7.03 , and the average value was 7.14. And the water temperature changed along with weather; in the first year, it rose from 24.5 to $27.9^{\circ} \mathrm{C}$ and dropped to $16.3{ }^{\circ} \mathrm{C}$, and the lowest temperature was $15.6{ }^{\circ} \mathrm{C}$. In the second year, it rose from 13.4 to $26.5^{\circ} \mathrm{C}$ and decreased to $15.8{ }^{\circ} \mathrm{C}$ with the minimum of $13.2{ }^{\circ} \mathrm{C}$.

Emitters

The experiment chose eight types of emitters, including four pressure-compensating emitters and four non-pressure-compensating emitters. The emitters are showed in Figs. 3, 4. The emitters hydraulic parameters were tested with the method suggested by $\mathrm{Li}$ et al. (2005), and the emitter parameters are shown in Table 2.

Experiment for emitter clogging of on-site reclaimed water drip irrigation

For each treatment, 60 emitters were selected and numbered from the inlet of the drip irrigation laterally (No. 1-60). The 120-micron disk filter was used at the head controlling part of the experimental system, which was shown in Fig. 5. The pressure of the flow was controlled by a flow-diversion system. An irrigation controller laid automatic control over the experimental system. The test started from 5/7/2010 and suspended on 14/11/2010 as weather got colder, then restated in 9/4/2011 and ended in 20/11/2011. Between the irrigation seasons, the laterals with emitters were rolled up, moved indoors carefully and kept in round, without heating or any other maintenance. The experimental system ran $3 \times 1 \mathrm{~h}$ cycles every other day, starting at 9:00, 15:00 and 21:00. The pressure of the flow is $0.1 \mathrm{MPa}$. In every $12 \mathrm{~h}$, the outflow of all emitters is tested for $3 \mathrm{~min}$ at the preliminary stage and in every $24 \mathrm{~h}$ after running $492 \mathrm{~h}$. The system pressure is corrected every time before outflow test to make sure it is steady at the designed value. The system run a total of $540 \mathrm{~h}$ during the two years, $204 \mathrm{~h}$ in the first year and run to the end after restarting in second year.

Corrected method for testing data of emitter outflows

The emitter outflow was mainly affected by multiple factors such as work pressure, manufacturing variability,

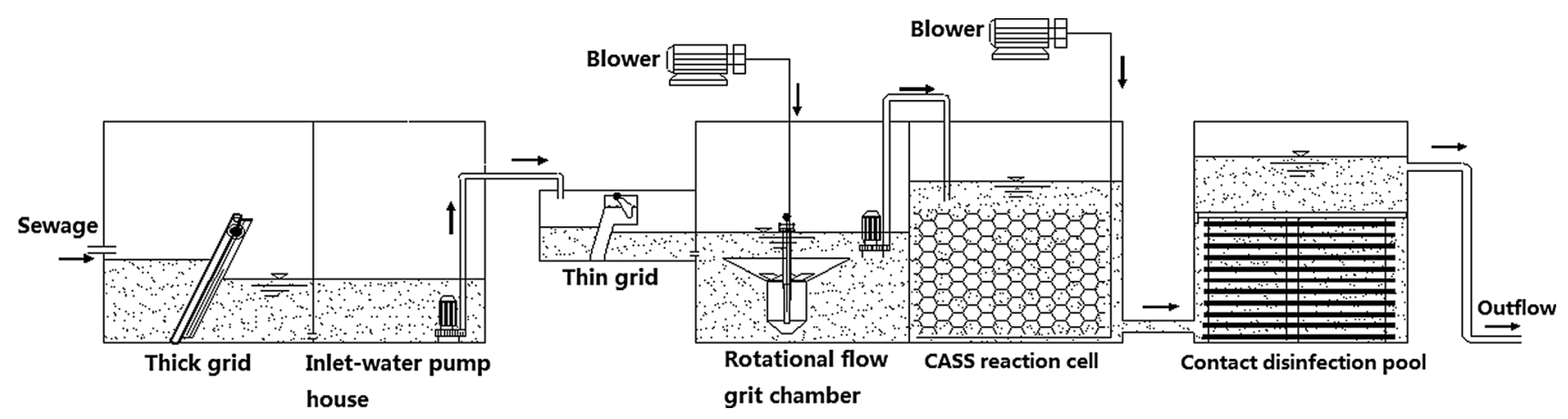

Fig. 1 Process of CASS wastewater treatment 
Table 1 Information of monitoring system instruments

\begin{tabular}{|c|c|c|c|}
\hline Analysis instruments & Manufacturer & Type & Measurement range \\
\hline COD automatic monitor & $\begin{array}{l}\text { YIWEN Environmental Science Technology } \\
\text { Co., ltd }\end{array}$ & EST-2001CODcr & $5-1,000 \mathrm{mg} / \mathrm{L}$ \\
\hline $\begin{array}{l}\text { Sludge level sensor and } \\
\text { transmitters }\end{array}$ & Endress + Hauser & $\begin{array}{l}\text { CUM253-TU005/ } \\
\text { CUS31-A4A }\end{array}$ & $0.001-300 \mathrm{mg} / \mathrm{L}$ \\
\hline $\mathrm{NH}_{4}{ }^{+}-\mathrm{N}$ monitor & WTW & TresCon UNO $\mathrm{NH}_{4}-\mathrm{N}$ & $\begin{array}{l}0-10 \mathrm{mg} / \mathrm{L} ; 10-100 \mathrm{mg} / \mathrm{L} \\
100-1000 \mathrm{mg} / \mathrm{L}\end{array}$ \\
\hline TP monitor & HUIHUAN DEK, China & DEK-1003 & $0.0-50.0 \mathrm{mg} / \mathrm{L}$ \\
\hline $\mathrm{pH}$ and temperature monitor & $\mathrm{HACH}$ & P53A4A1 N/PD1R1/ & $0.0-50.0 \mathrm{mg} / \mathrm{L}$ \\
\hline
\end{tabular}

water temperature and clogging degree (Nakayama and Bucks 1991; Ravina et al. 1992; Provenzano and Pumo 2004). Field experiment could restore the real emitter work circumstance and comparatively accurately reflected the clogging behavior during field work. However, environment would affect the field test, causing outflow deviation. In order to get the independent clogging influence value $\Delta q_{C_{i}}$, it is necessary to correct the actual measured outflow to eliminate the influence of alternation in emitter work pressure as a neighboring clog and water temperature. The water temperature or tested emitter number will differ significantly after the field experiment lasts a long time.

Number all the emitters on lateral from 1 to $n$ along water flow. Record every emitter outflow as $q_{m_{i}}(i=1$, $2, \ldots, n ; n$ is the total number of emitters). Assuming that $q_{m_{i}}$ was the outflow of emitters measured at anytime, equal to the sum of $\Delta q_{T_{i}}$ (deviation caused by water temperature), $\Delta q_{C_{i}}$ (deviation caused by clogging) and $\Delta q_{H_{i}}$ (deviation caused by actual work pressure). The three values were mutually independent.

\section{1. $\Delta q_{T_{i}}$}

According to the equation of linear regression between outflow and the index $x$, as well as the linear relation between outflow and temperature, we can get the relationship between water temperature $T_{i}$ and rated outflow under $20^{\circ} \mathrm{C}$, as shown in Eq. 1, to eliminate the deviation caused by water temperature.

$q_{T_{i}}=\left(1+\frac{57.35 x-28.24}{100} \times \frac{T_{i}-20}{20}\right) \times q_{20}$

$\Delta q_{T_{i}}=\frac{57.35 x-28.24}{100} \times \frac{T_{i}-20}{20} \times q_{20}$

where $q_{T_{i}}\left(\mathrm{~m}^{3} / \mathrm{s}\right)$ was the corrected outflow by temperature; $q_{20}\left(\mathrm{~m}^{3} / \mathrm{s}\right)$ was the designed outflow under $20{ }^{\circ} \mathrm{C}$. They were assumed to be same on the same lateral and offered by the manufacturer or measured before experiment. $x$ was the flow stance index of emitters, offered by the manufacturer; $T_{i}$ was the water temperature, and $\Delta q_{T_{i}}$ represented the difference between $q_{T_{i}}$ and $q_{20}$,

\section{2. $\Delta q_{H_{i}}$}

According to the relation between emitter outflow and pressure,

$q_{m_{i}}^{\prime}=k h_{i}^{x}$

where $k$ and $x$ were the flow coefficient and flow stance index, offered by the manufacturer; $h_{i}$ was the work pressure of emitter $i ; q_{m_{i}}^{\prime}$ was the unclogged outflow under the pressure $h_{i}$.

At this time, the main job of pressure correction was transformed into calculating the actual work pressure of every emitter $h_{i}$. The calculating processes of $h_{i}$ was shown as follows.

The cross section of lateral inlet is needed to calculate $h_{1}$. The process was similar to calculate pressure when $i \geq 1$, so it can be regarded as the special application of the calculate processes of $i \geq 1$. The calculate process of $\mathrm{h}_{\mathrm{i}}$ was discussed in two parts:

(a) When $i=0$, calculate the actual work pressure $\left(h_{1}\right)$ of the first emitter. The pressure of lateral inlet cross section was indicated by pressure gauge-the designed pressure $H$. Take the measured outflow value $q_{m_{i}}$ into equations for calculation and get $h_{1}$.

(b) When $i \geq 1$, taking $h_{1}$ into equations and calculate $h_{2}$, repeated the process until getting the actual work pressure of all the emitters' cross section. The distance of two sections was the space between emitters, and it was constant during single lateral adjustment.

The Bernoulli equation of two adjacent sections is rewrite as,

$\left\{\begin{array}{l}H+\frac{2 Q_{i}^{2}}{\pi D^{2} \cdot g}=h_{i+1}+\frac{2 Q_{i+1}^{2}}{\pi D^{2} \cdot g}+h_{w_{i}} \quad i=0, \\ h_{i}+\frac{2 Q_{i}^{2}}{\pi D^{2} \cdot g}=h_{i+1}+\frac{2 Q_{i+1}^{2}}{\pi D^{2} \cdot g}+h_{w_{i}} \quad i \geq 1 .\end{array}\right.$

where $Q_{i}$ and $Q_{i+1}$ were the lateral outflow of two adjacent sections, $Q_{i}=\sum_{i=\mathrm{i}+1}^{n} q_{m_{i}}$, that was, the outflow of section $i-Q_{i}\left(\mathrm{~m}^{3} / \mathrm{s}\right)$, equal to the sum of all the emitters behind 
Fig. 2 Daily water quality monitoring in Beiqijia sewage treatment plant
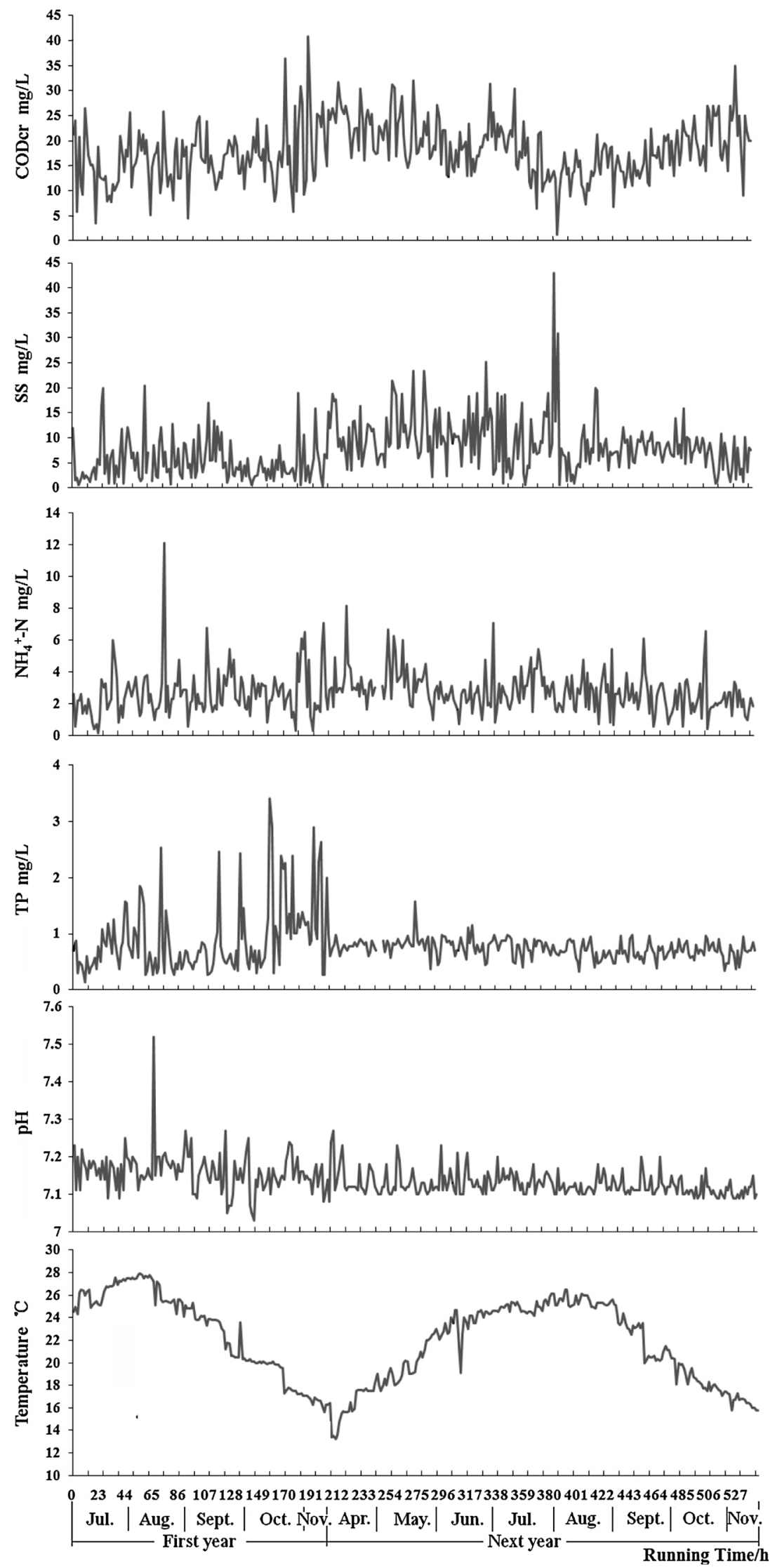


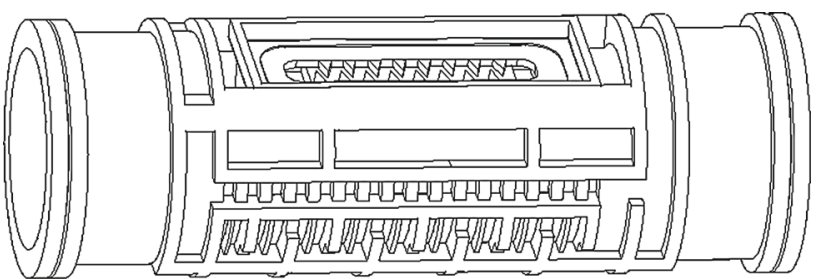

(a) ADI Cylindrical PC (Pressure Compensated) dripper ( $\left.\mathrm{E}_{1}\right)$

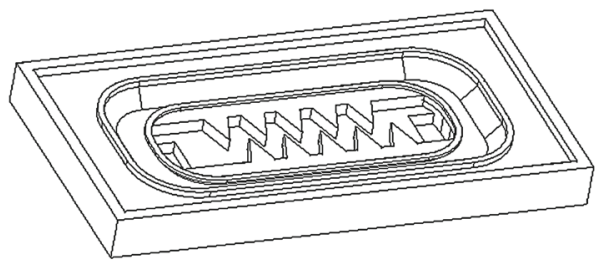

(b) VARDIT Miniature flat PC dripper $\left(\mathrm{E}_{2}\right)$

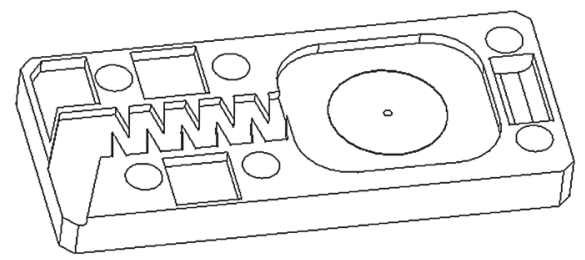

(c) Netafim flat PC dripper $\left(\mathrm{E}_{3}\right)$

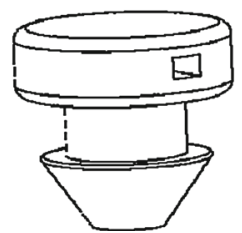

(d) Online PC dripper $\left(\mathrm{E}_{4}\right)$

Fig. 3 Pressure-compensating emitters

the section; $D(\mathrm{~m})$ was the diameter of lateral; $h_{w_{i}}(\mathrm{~m})$ was the head loss between two sections.

The head loss of two adjacent sections was calculated by using the equation in microirrigation engineering standard.

$h_{f_{i}}=\lambda \frac{Q_{i}^{A}}{D^{B}} L_{i}$

where $h_{f_{i}}$ was the frictional head loss, $m$; $\lambda$ was the friction factor of head loss; $Q_{i}$ was the lateral flow as Eq. 2, $L_{i}$ was the section length, $m ; A$ was the index of outflow; $B$ was the index of lateral. $A$ and $B$ were chosen as 1.75 and 4.75 according to the reference of frictional head loss coefficient and index; $\lambda$ was 0.505 at $10{ }^{\circ} \mathrm{C}$, and should multiplied with the water temperature correction factor $\alpha$ when temperature varies, $\alpha$ take $1.038,0.966,0.937,0.910,0.844$ to calculate while the temperatures were $5,10,15,25,30^{\circ} \mathrm{C}$, respectively. If under other temperatures, $\alpha$ was calculated using the interpolation method.

Considering that the lateral has multiple outlets, a coefficient needs to be multiplied on when calculating the frictional head loss of lateral. So in this method, we also needed to consider the effect of the multiple coefficients. The common calculate equation is Christiansen Equation:

$F=\frac{n\left(\frac{1}{m+1}+\frac{1}{2 n}+\frac{\sqrt{m-1}}{6 n^{2}}\right)-1+\sigma}{n-1+\sigma}$

where $F$ was the multiple coefficient; $n$ was number of emitters; $m$ was the lateral index, which should be selected in relative table; $\sigma$ was the rate between the distance between lateral inlet and the first emitter cross section and the emitter space.

The local head loss between two adjacent cross sections was a certain percentage of frictional head loss.

$h_{j_{i}}=f_{c} \cdot h_{f_{i}}$

where $f_{c}$ was the percentage. It was calculated by the coefficient estimate equation put forward by Chen and Zheng (1994).

$f_{c}=\frac{19 B_{w}}{4 D^{1.9}} \cdot a \cdot S_{e}^{b} \cdot H^{c}$

where $B_{w}$ was the diameter of emitter, $\mathrm{mm} ; D$ was the lateral diameter, $\mathrm{mm} ; S_{e}$ was the emitter space, $m ; H$ was the lateral inlet designed pressure, $m ; a, b, c$ were 1.59 , -0.67 , and -0.43 , respectively.

Then the head loss of two adjacent sections was,

$h_{w_{i}}=\left(F+f_{c}\right) \times h_{f_{i}}$

where $F$ was a constant, equal to the value of $f_{c}$ in Eqs. 7 and 8.

Figure out all the actual working pressure $h_{i}$. Taking them into Eq. 3 and got $q_{m_{i}}^{\prime}$. Then the outflow deviation caused by working pressure changing $\left(\Delta q_{H_{i}}\right)$ was,

$q_{i}=q_{20}+\Delta q_{C_{i}}$

\section{3. $\Delta q_{C_{i}}$}

The difference on outflow caused by other clogged emitters, $\Delta q_{C_{i}}$, could be calculated by

$\Delta q_{C_{i}}=q_{m_{i}}-q_{20}-\Delta q_{T_{i}}-\Delta q_{H_{i}}$

Then the correctional flow $q_{i}$, which considering the influence of clogged emitters only, was 
Fig. 4 Non-pressurecompensating emitters

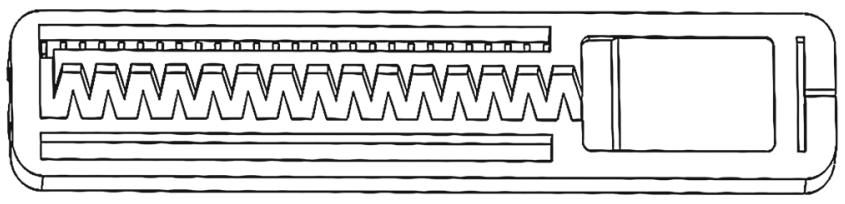

(a) Cusp-shaped saw-tooth $\left(\mathrm{E}_{5}\right)$

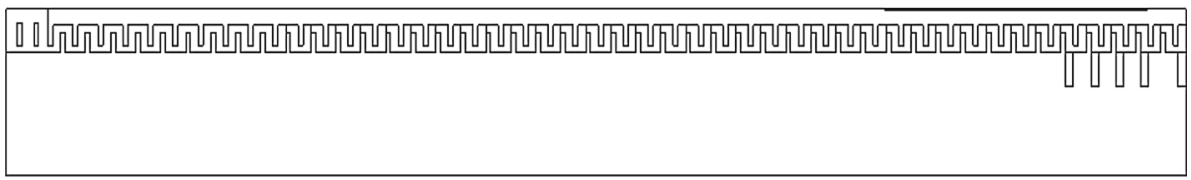

(b) Rectangular straight-tooth $\left(\mathrm{E}_{6}\right)$

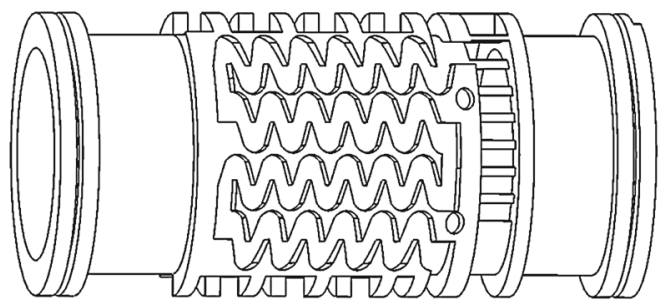

(c) Arc-shaped saw-tooth $\left(\mathrm{E}_{7}\right)$

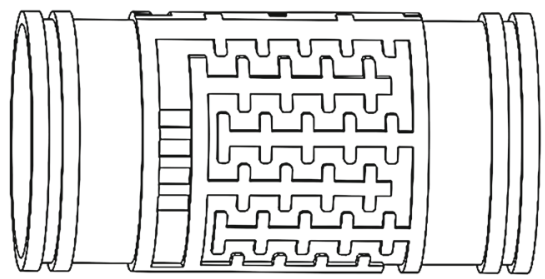

(d) Arc-angular straight-tooth $\left(\mathrm{E}_{8}\right)$

Table 2 Characteristic parameters of tested emitters

\begin{tabular}{|c|c|c|c|c|c|c|c|}
\hline Number & Emitter type/flow & path type & $\begin{array}{l}\text { Flow path geometric parameters/ } \\
\text { length } \times \text { width } \times \text { depth }(\mathrm{mm})\end{array}$ & $\begin{array}{l}\text { Emitter } \\
\text { flow } \\
q(\mathrm{~L} / \mathrm{h})\end{array}$ & $\begin{array}{l}\text { Producing } \\
\text { area }\end{array}$ & $\begin{array}{l}\text { Flow } \\
\text { stance } \\
\text { index } x\end{array}$ & $\begin{array}{l}\text { Flow } \\
\text { coefficient } \\
K_{d}\end{array}$ \\
\hline $\mathrm{E}_{1}$ & $\begin{array}{l}\text { Pressure- } \\
\text { compensating } \\
\text { Emitters }\end{array}$ & ADI cylindrical PC dripper & - & 3.8 & Israel & 0.13 & 2.85 \\
\hline $\mathrm{E}_{2}$ & & $\begin{array}{l}\text { VARDIT Miniature flat PC } \\
\text { dripper }\end{array}$ & - & 1.2 & Israel & 0.24 & 0.71 \\
\hline $\mathrm{E}_{3}$ & & Netafim flat PC dripper & - & 1.0 & Israel & 0.23 & 0.59 \\
\hline $\mathrm{E}_{4}$ & & Online PC dripper & $\longrightarrow$ & 2.9 & China & 0.26 & 1.6 \\
\hline $\mathrm{E}_{5}$ & $\begin{array}{l}\text { Non-pressure- } \\
\text { compensating } \\
\text { emitters }\end{array}$ & $\begin{array}{l}\text { Integral flat dripper/Cusp- } \\
\text { shaped saw-tooth }\end{array}$ & $50.23 \times 0.57 \times 0.67$ & 1.0 & Israel & 0.51 & 0.31 \\
\hline $\mathrm{E}_{6}$ & & $\begin{array}{l}\text { Single wing side opening } \\
\text { dripper/rectangular } \\
\text { straight-tooth }\end{array}$ & $450.04 \times 1.68 \times 0.78$ & 3.1 & China & 0.57 & 0.83 \\
\hline $\mathrm{E}_{7}$ & & $\begin{array}{l}\text { Cylindrical dripper/arc- } \\
\text { shaped saw-tooth }\end{array}$ & $142.35 \times 1.27 \times 0.99$ & 2.9 & China & 0.52 & 0.89 \\
\hline $\mathrm{E}_{8}$ & & $\begin{array}{l}\text { Cylindrical dripper/arc- } \\
\text { angular straight-tooth }\end{array}$ & $152.23 \times 2.40 \times 0.83$ & 1.8 & China & 0.51 & 0.56 \\
\hline
\end{tabular}




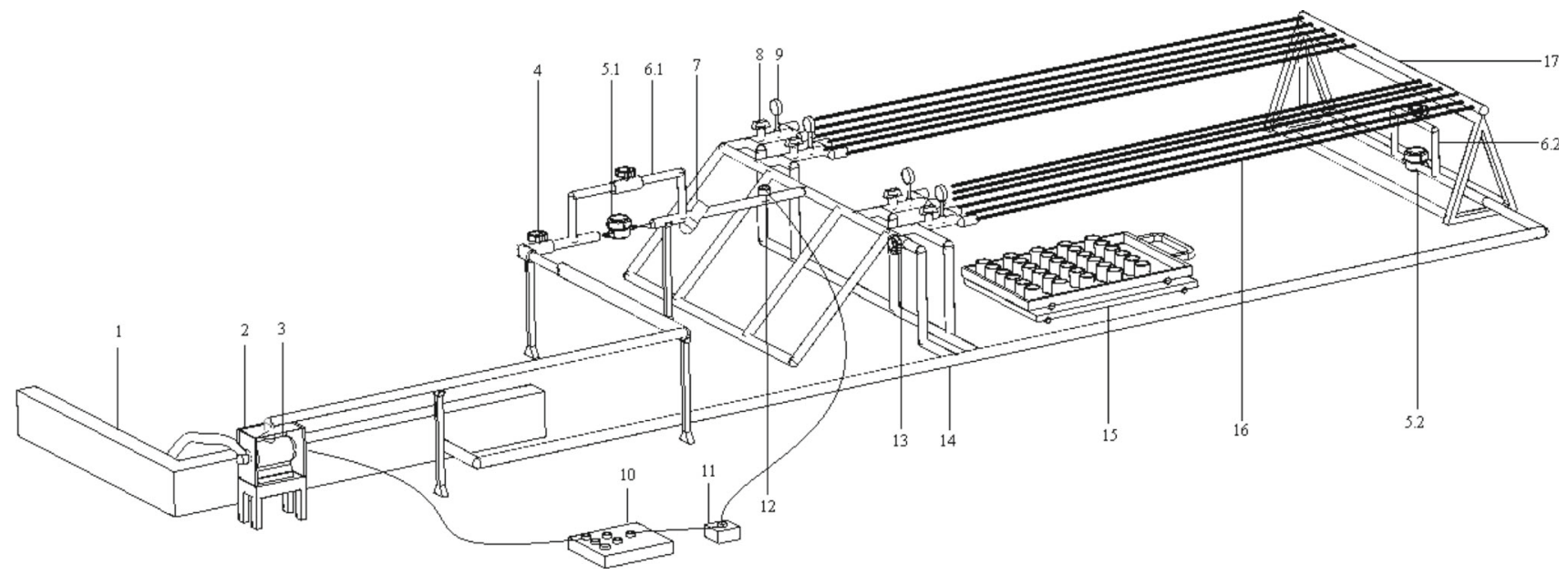

1-reclaimed water; 2-water pump protector; 3-water pump; 4-valve; 5.1、5.2-water meter; 6.1、6.2-water meter protection pipe; 7-filter; 8-pressure fine-tuning valve; 9-pressure gage; 10- distribution box; 11-automatic irrigation controller; 12-magnetic valve; 13- side valve; 14-return pipe; 15-flow testing unit; 16-drip irrigation tube; 17-terminal return pipe

Fig. 5 Experimental settings

$q_{i}=q_{20}+\Delta q_{C_{i}}$.

Evaluating emitter clogging characteristics

During the experiment, the outflow of all emitters is tested for $3 \mathrm{~min}$ at the preliminary $492 \mathrm{~h}$ every $12 \mathrm{~h}$ and in every $24 \mathrm{~h}$ from $492 \mathrm{~h}$ to $540 \mathrm{~h}$, and the recorded data were analyzed by taking the average of two repeated groups.

\section{Dra}

The relative average discharge of drip irrigation emitters (Yan et al. 2011) was calculated in Eq. 13:

Dra $=\frac{\sum_{i=1}^{n} q_{i}}{n q_{20}} \times 100 \%$

where $q_{i}$ indicated the flow of drip irrigation emitter $i(\mathrm{~L} / \mathrm{h})$, $q_{20}$ was the drip emitter rated outflow under $20^{\circ} \mathrm{C}(\mathrm{L} / \mathrm{h})$, and $n$ was the total number of experimental emitters.

\section{2. $\mathrm{CU}$}

The outflow uniformity of the drip irrigation emitters could be represented by uniformity coefficient $\mathrm{CU}$ (Eq. 14), which reflected the randomness during emitter clogging.

$\mathrm{CU}=100\left(1-\frac{\sum_{i=1}^{n}\left|q_{i}-\bar{q}\right|}{n \bar{q}}\right)$

where $\bar{q}$ was the average correctional emitter outflow (L/h).

3. Emitter clogging rate distribution

The emitter clogging distribution was represented as the percentage calculated by a single emitter's outflow divided by initial outflow. The percentage of a single emitter outflow was calculated firstly, and the number of drip irrigation emitters within different percentage ranges was then calculated separately. Finally, the proportion of emitters within each percentage range was obtained.

In general, a single emitter was defined as unclogged if its outflow was higher than $95 \%$ of the initial flow, while $80-95 \%$ was defined as slightly clogged, $50-80 \%$ was defined as generally clogged, $20-50 \%$ was defined as seriously clogged, and $<20 \%$ was defined as completely clogged (Wu 2006). The changes in the distribution of different clogging degrees in a drip irrigation system were counted in head part (No. 0-20), middle part (No. 21-40) and tail (No. 41-60) part of the lateral, respectively. Considering two repeated treatments, totally 120 emitters were included, and 40 in each part (head, middle and tail).

\section{Results and analysis}

Dynamic changes for outflow ratio variation of emitters

The experiment operated for $540 \mathrm{~h}$. Dynamic average relative outflow changes of eight emitters were shown in Fig. 6, and average relative outflow linear variation fitting parameters and significance $t$ test results were shown in Table 3. As shown in Fig. 6, the average relative outflow varied in three periods which were, the fluctuated balance period, the initiate linear period and the accelerated linear period. Obvious differences were observed between emitters in each period. 
In the beginning of the experiment, during the fluctuated balance period, the Dra of emitters changed fluctuated slightly, and the vacation range was within $3.47 \%$. Emitter clogging appeared mainly in local position of the lateral and had small difference on Dra, being less significant.

As the system kept running, the variation escalated to the initiate linear changing period and emitter clogging started affecting Dra variation. Dra of different emitters reduced 4.1-13.1\% at the first year. But the linear starting times of initiate linear period were different between different types of emitters, among which the pressure-compensating emitters started at 72-108 h, and the nonpressure-compensating started at 60-72 h. Dra varied generally in linear during the period of time, and t-check results of pressure-compensating emitters were not significant except $E_{1}$, but all those non-pressure-compensating ones breached linear significance level. $k_{l}$ varied from
Fig. 6 Changes in dynamic average relative outflows of 8 types of emitters
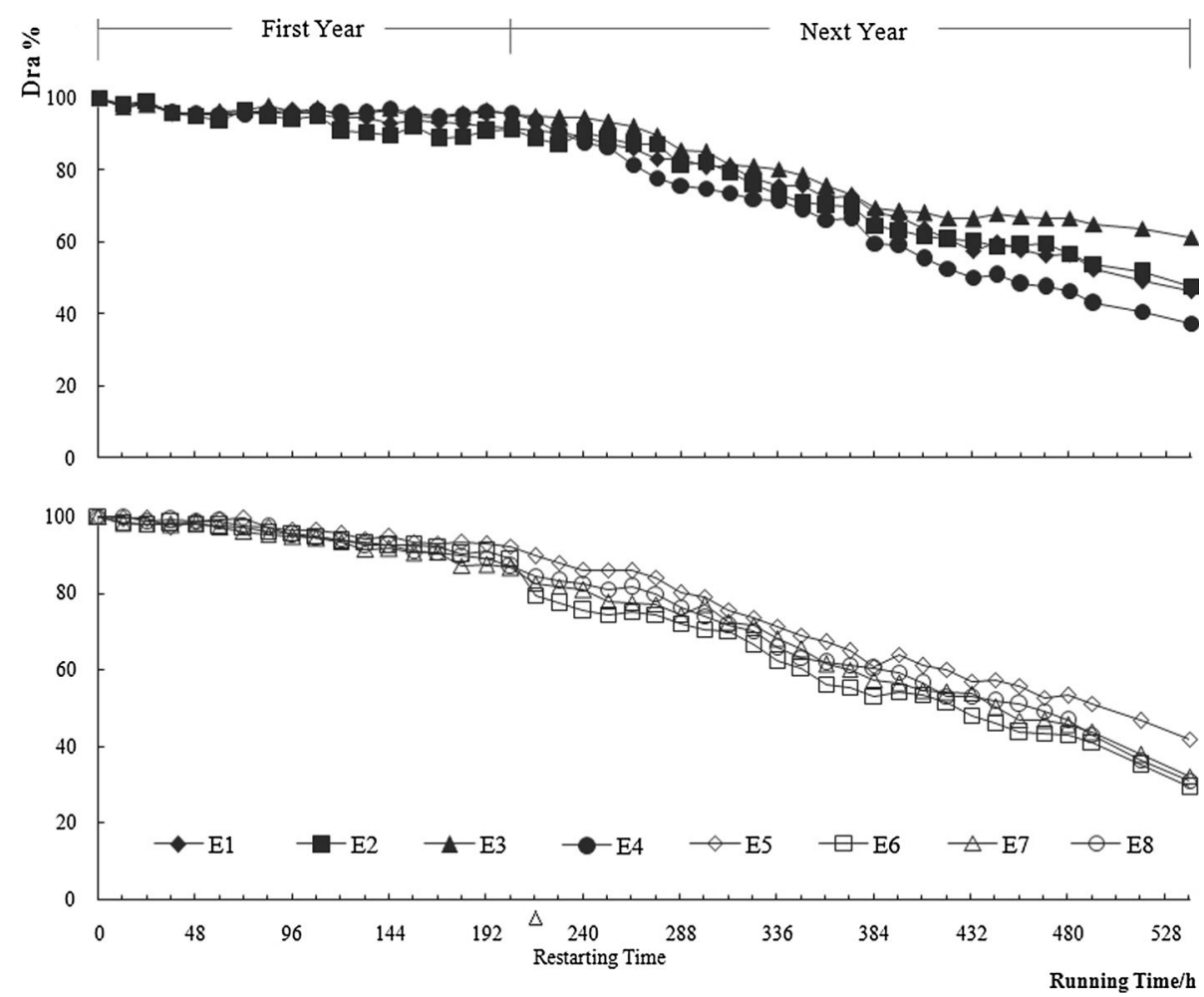

Table 3 Average relative outflow variation parameters of 8 typeset of emitters

\begin{tabular}{|c|c|c|c|c|c|c|c|c|c|c|c|c|c|c|c|c|c|c|c|c|c|}
\hline \multirow[t]{4}{*}{ Number } & \multicolumn{11}{|l|}{ First year $(0-204 \mathrm{~h})$} & \multirow{2}{*}{\multicolumn{10}{|c|}{$\frac{\text { Next year }(204-540 \mathrm{~h})}{\text { Accelerated linear period }}$}} \\
\hline & \multirow{3}{*}{$\begin{array}{l}\text { Fluctuated balance } \\
\text { period }\end{array}$} & \multicolumn{10}{|c|}{ Initiate linear period } & & & & & & & & & & \\
\hline & & \multicolumn{2}{|c|}{ Linear fitting } & \multicolumn{8}{|c|}{ T-check results } & \multicolumn{2}{|c|}{ Linear fitting } & \multicolumn{8}{|c|}{ T-check results } \\
\hline & & $K_{1}$ & $R^{2}$ & $\mathrm{E}_{1}$ & $\mathrm{E}_{2}$ & $\mathrm{E}_{3}$ & $\mathrm{E}_{4}$ & $\mathrm{E}_{5}$ & $\mathrm{E}_{6}$ & $\mathrm{E}_{7}$ & $\mathrm{E}_{8}$ & $K_{2}$ & $R^{2}$ & $\mathrm{E}_{1}$ & $\mathrm{E}_{2}$ & $\mathrm{E}_{3}$ & $\mathrm{E}_{4}$ & $\mathrm{E}_{5}$ & $\mathrm{E}_{6}$ & $\mathrm{E}_{7}$ & $\mathrm{E}_{8}$ \\
\hline $\mathrm{E}_{1}$ & $0-96 \mathrm{~h}$ & -0.038 & 0.92 & - & - & - & - & - & - & - & - & -0.145 & 0.99 & - & - & - & - & - & - & - & - \\
\hline $\mathrm{E}_{2}$ & $0-72 \mathrm{~h}$ & -0.046 & 0.60 & $* *$ & - & - & - & - & - & - & - & -0.138 & 0.97 & $\mathrm{~N}$ & - & - & - & - & - & - & - \\
\hline$E_{3}$ & $0-84 \mathrm{~h}$ & -0.010 & 0.25 & $* *$ & $* *$ & - & - & - & - & - & - & -0.115 & 0.94 & $* *$ & $* *$ & - & - & - & - & - & - \\
\hline $\mathrm{E}_{4}$ & $0-108 \mathrm{~h}$ & -0.005 & 0.10 & $* *$ & $* *$ & $\mathrm{~N}$ & - & - & - & - & - & -0.173 & 0.99 & $* *$ & $* *$ & $* *$ & - & - & - & - & - \\
\hline $\mathrm{E}_{5}$ & $0-72 \mathrm{~h}$ & -0.047 & 0.91 & - & - & - & - & - & - & - & - & -0.147 & 0.99 & - & - & - & - & - & - & - & - \\
\hline $\mathrm{E}_{6}$ & $0-60 \mathrm{~h}$ & -0.056 & 0.97 & - & - & - & - & $* *$ & - & - & - & -0.151 & 0.98 & - & - & - & - & $* *$ & - & - & - \\
\hline $\mathrm{E}_{7}$ & $0-60 \mathrm{~h}$ & -0.074 & 0.97 & - & - & - & - & $* *$ & $* *$ & - & - & -0.155 & 0.99 & - & - & - & - & $* *$ & $* *$ & - & - \\
\hline$E_{8}$ & $0-72 \mathrm{~h}$ & -0.073 & 0.98 & - & - & - & - & $* *$ & $*$ & $* *$ & - & -0.159 & 0.99 & - & - & - & - & $* *$ & $* *$ & $\mathrm{~N}$ & - \\
\hline
\end{tabular}

Dra $=K_{1,2} \times t+c, t$ is the total running time of the system, $K_{1,2}$ is the average relative outflow linear variation fitting gradients of initiate linear period and accelerated linear period, $c$ is the average relative outflow linear variation fitting parameter, as it has no real significance and is out of analysis. $\mathrm{N}$ means not significant, $*$ means significant $(p<0.05)$, and $* *$ means very significant $(p<0.01)$ 
-0.073 to -0.047 . The difference between emitters was larger and the pressure-compensating emitters ranked as Dra $_{E_{4}}>$ Dra $_{E_{3}}>$ Dra $_{E_{1}}>$ Dra $_{E_{2}}$. The differences between $E_{1}$ and $E_{2}$ were not significant, as well as $E_{3}$ and $E_{4}$, while other pressure-compensating ones differed with great significance $(p<0.01)$. Non-pressure-compensating emitters ranked as Dra $_{\mathrm{E}_{5}}>$ Dra $_{\mathrm{E}_{6}}>$ Dra $_{\mathrm{E}_{8}}>$ Dra $_{\mathrm{E}_{7}}$, and differences between $E_{5}$ and $E_{7}, E_{5}$ and $E_{8}, E_{6}$ and $E_{8}$ were small while others reached the significance level $(p<0.05)$. The period lasted until the end of first year test.

After the restarting in the 2nd year, some emitters' Dra dropped abruptly; the maximum drop range was $9.6 \%$. Then they all entered the accelerated linear period and showed a obvious linear decrease trend $\left(R^{2}>0.94\right)$, and $k_{2}$ varied from -0.173 to -0.115 in pressure-compensating emitters and -0.073 to -0.047 in non-pressure-compensating emitters. It indicated that the outflow and clogging trends of 4 non-pressure-compensating emitters had a small difference in the 2nd year, and their Dra differed within $7.5 \%$. Overall, the Dra differences between emitters were obvious, 4 pressure-compensating emitters ranked as Dra $_{\mathrm{E}_{3}}>$ Dra $_{\mathrm{E}_{2}}>$ Dra $_{\mathrm{E}_{1}}>$ Dra $_{\mathrm{E}_{4}}$ and 4 non-pressure-compensating emitters ranked as Dra $_{\mathrm{E}_{5}}>$ Dra $_{\mathrm{E}_{7}}>$ Dra $_{\mathrm{E}_{8}}>$ Dra $_{\mathrm{E}_{6}}$. Most of those differences between emitters reached the significant level, except $E_{1}$ and $E_{2}, E_{7}$ and $E_{8}$. However, the result differed during the initiate linear period. In the end of this period, pressure-compensating emitters Dra reduced to 37.5-67.3\% and non-pressure-compensating reduced to 29.3-41.9\%, and most of emitters were seriously clogged or completely clogged.

In general, Dra of 4 non-pressure-compensating emitters decreased more than 4 pressure-compensating emitters, indicating that pressure-compensating emitters had a stronger suitability and better anti-clogging ability in reclaimed water drip irrigation.

Dynamic changes for irrigation uniformity coefficient of emitters

Irrigation uniformity variation of 8 types of emitters was shown in Fig. 7, and irrigation uniformity linear variation fitting parameters and t-check results were shown in Table 4. As shown above, irrigation uniformity also varied in three periods.

In the fluctuated balance period, the CU changed fluctuated slightly, and the range was within $4.97 \%$. Emitters clogged slightly, and made small difference on CU.

As the system running, $\mathrm{CU}$ variation escalated to initiate linear period, where emitter clogging started showing its influences. The starting times were the same to Dra. As a whole, CU varied in linear $\left(R^{2}>0.86\right)$, but the varying rate differed between emitters. Generally, CU variation gradient of pressure-compensating emitters were higher than non-pressure-compensating emitters, $k_{1}$ varied from -0.037 to -0.112 for pressure-compensating emitters and from -0.042 to -0.094 for non-pressure-compensating
Fig. 7 Changes in dynamic irrigation uniformities of 8 types of emitters

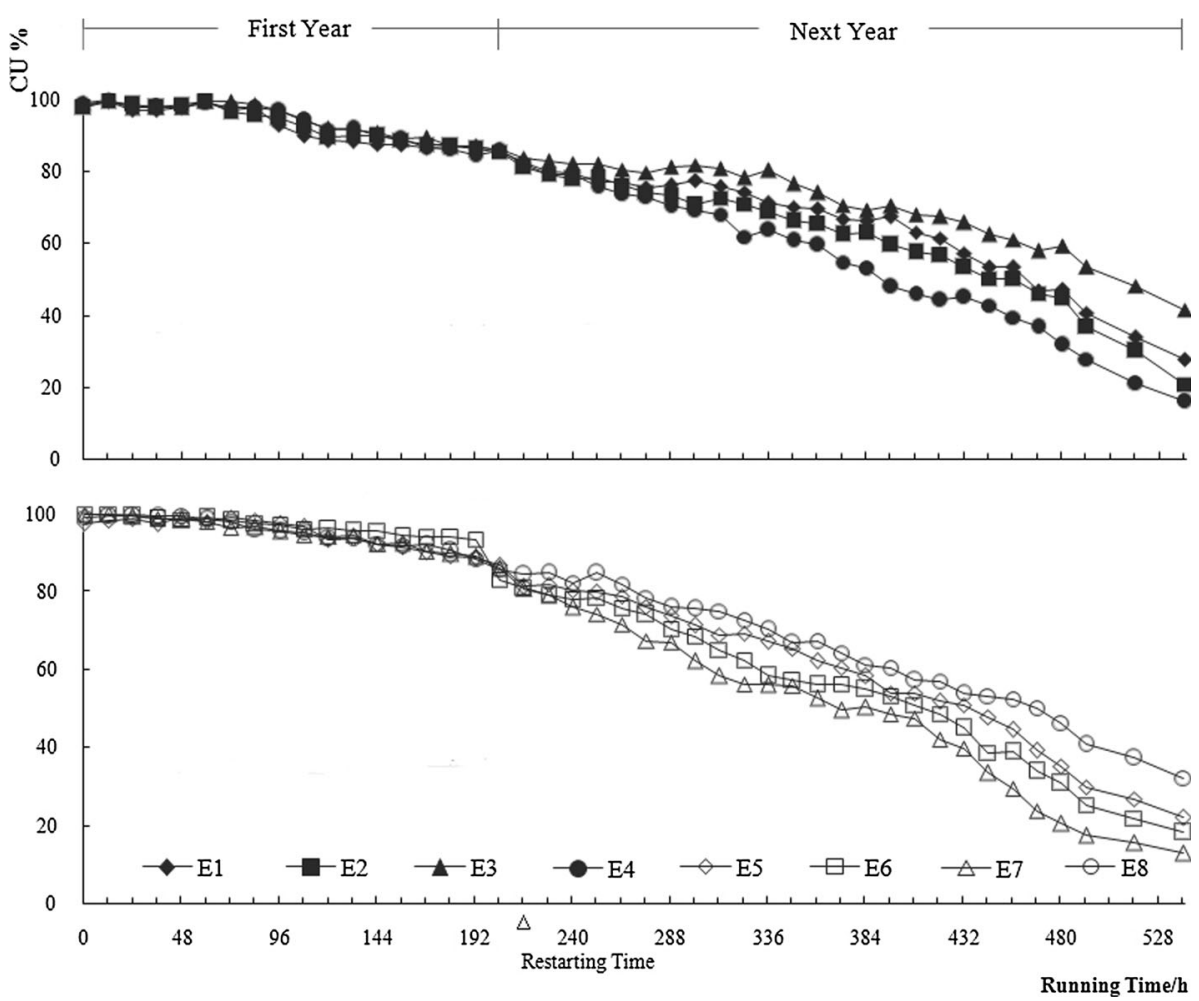


Table 4 Irrigation uniformity variation parameters of 8 typeset of emitters

\begin{tabular}{|c|c|c|c|c|c|c|c|c|c|c|c|c|c|c|c|c|c|c|c|c|c|}
\hline \multirow[t]{4}{*}{ Number } & \multicolumn{11}{|l|}{ First year $(0-204 \mathrm{~h})$} & \multirow{2}{*}{\multicolumn{10}{|c|}{$\frac{\text { Next year }(204-540 \mathrm{~h})}{\text { Accelerated linear period }}$}} \\
\hline & \multirow{3}{*}{$\begin{array}{l}\text { Fluctuated balance } \\
\text { period }\end{array}$} & \multicolumn{10}{|c|}{ Initiate linear period } & & & & & & & & & & \\
\hline & & \multicolumn{2}{|c|}{ Linear fitting } & \multicolumn{8}{|c|}{ T-check results } & \multicolumn{2}{|c|}{ Linear fitting } & \multicolumn{8}{|c|}{ T-check results } \\
\hline & & $\mathrm{K}_{3}$ & $R^{2}$ & $\mathrm{E}_{1}$ & $\mathrm{E}_{2}$ & $\mathrm{E}_{3}$ & $\mathrm{E}_{4}$ & $\mathrm{E}_{5}$ & $\mathrm{E}_{6}$ & $\mathrm{E}_{7}$ & $\mathrm{E}_{8}$ & $\mathrm{~K}_{4}$ & $R^{2}$ & $\mathrm{E}_{1}$ & $\mathrm{E}_{2}$ & $E_{3}$ & $\mathrm{E}_{4}$ & $\mathrm{E}_{5}$ & $\mathrm{E}_{6}$ & $\mathrm{E}_{7}$ & $\mathrm{E}_{\varnothing}$ \\
\hline $\mathrm{E}_{1}$ & $0-96 \mathrm{~h}$ & -0.051 & 0.79 & - & - & - & - & - & - & - & - & -0.150 & 0.91 & - & - & - & - & - & - & - & - \\
\hline $\mathrm{E}_{2}$ & $0-72 \mathrm{~h}$ & -0.083 & 0.94 & $*$ & - & - & - & - & - & - & - & -0.162 & 0.94 & $* *$ & - & - & - & - & - & - & - \\
\hline $\mathrm{E}_{3}$ & $0-84 \mathrm{~h}$ & -0.100 & 0.93 & $* *$ & $* *$ & - & - & - & - & - & - & -0.117 & 0.92 & $* *$ & $* *$ & - & - & - & - & - & - \\
\hline $\mathrm{E}_{4}$ & $0-108 \mathrm{~h}$ & -0.112 & 0.95 & $\mathrm{~N}$ & $\mathrm{~N}$ & $\mathrm{~N}$ & - & - & - & - & - & -0.198 & 0.99 & $* *$ & $* *$ & $* *$ & - & - & - & - & - \\
\hline$E_{5}$ & $0-72 \mathrm{~h}$ & -0.094 & 0.98 & - & - & - & - & - & - & - & - & -0.186 & 0.98 & - & - & - & - & - & - & - & - \\
\hline $\mathrm{E}_{6}$ & $0-60 \mathrm{~h}$ & -0.042 & 0.97 & - & - & - & - & $*$ & - & - & - & -0.200 & 0.98 & - & - & - & - & $* *$ & - & - & - \\
\hline$E_{7}$ & $0-60 \mathrm{~h}$ & -0.079 & 0.94 & - & - & - & - & $\mathrm{N}$ & $* *$ & - & - & -0.216 & 0.98 & - & - & - & - & $* *$ & $* *$ & - & - \\
\hline $\mathrm{E}_{8}$ & $0-72 \mathrm{~h}$ & -0.076 & 0.96 & - & - & - & - & $\mathrm{N}$ & $* *$ & $\mathrm{~N}$ & - & -0.159 & 0.98 & - & - & - & - & $* *$ & $* *$ & $* *$ & - \\
\hline
\end{tabular}

$\operatorname{Dra}=K_{3,4} \times t+c, K_{3,4}$ is the irrigation uniformity linear variation fitting gradients of initiate linear period and accelerated linear period, other symbols mean the same as above

emitters. The difference between emitters appeared and the pressure-compensating emitters ranked as $\mathrm{CU}_{\mathrm{E}_{3}}>\mathrm{CU}_{\mathrm{E}_{4}}>$ $\mathrm{CU}_{\mathrm{E}_{1}}>\mathrm{CU}_{\mathrm{E}_{2}}$. The differences between $\mathrm{E}_{1}, \mathrm{E}_{2}$ and $\mathrm{E}_{3}$ were significant $(p<0.05)$, as well as $\mathrm{E}_{2}$ and $\mathrm{E}_{4}$. Non-pressurecompensating emitters ranked as $\mathrm{CU}_{\mathrm{E}_{6}}>\mathrm{CU}_{\mathrm{E}_{5}}>\mathrm{CU}_{\mathrm{E}_{7}}>$ $\mathrm{CU}_{\mathrm{E}_{8}}$ and differences between $\mathrm{E}_{5}, \mathrm{E}_{7}$ and $\mathrm{E}_{8}$ reached the significance level $(p<0.05)$.

After restarting in the 2nd year, emitters' CU dropped abruptly, and they all entered the accelerated linear period. $\mathrm{CU}$ of pressure-compensating emitters and non-pressurecompensating emitters decreased to $15.8-41.5 \%$ and $12.7-$ $32.0 \%$, respectively. In comparison, non-pressure-compensating emitters could do better in keeping the irrigation uniformity. And all emitters showed an obvious linear decrease trend $\left(R^{2}>0.91\right), k_{2}$ varied from -0.198 to -0.117 for pressure-compensating emitters and from -0.200 to -0.159 for non-pressure-compensating emitters. Overall, the $\mathrm{CU}$ differences between emitters all reached the significant level $(p<0.01), 4$ pressure-compensating emitters ranked as $\mathrm{CU}_{\mathrm{E}_{3}}>\mathrm{CU}_{\mathrm{E}_{1}}>\mathrm{CU}_{\mathrm{E}_{2}}>\mathrm{CU}_{\mathrm{E}_{4}}$ and 4 non-pressure-compensating emitters ranked as $\mathrm{CU}_{\mathrm{E}_{8}}>\mathrm{CU}_{\mathrm{E}_{5}}>$ $\mathrm{CU}_{\mathrm{E}_{6}}>\mathrm{CU}_{\mathrm{E}_{7}}$.

Dynamic changes for clogging rate distribution of emitter in different lateral location

The dynamic changes of clogging distribution in both pressure-compensating and non-pressure-compensating emitters at the head, middle and end parts of the lateral were shown in Figs. 8, 9.

As shown above, we can see that emitters clogging had been getting worse as system continued on running. Emitters' clogging always began within $36-48 \mathrm{~h}$. In the first year, most emitters clogged slightly. There were generally no clogged emitters found at the middle and end of the lateral (under $4.16 \%$ ). Unclogged emitters accounted for 61.4 and $58.9 \%$ for pressure-compensating and non-pressure-compensating emitters, respectively.

After restarted the system in the following year, emitters clogged rapidly. Serious and complete clogging appeared within 216-252 h and 252-264 h, respectively, and increased undulant. The clogging distributions of 8 emitters were as follows: unclogged emitters of ADI Cylindrical PC (Pressure Compensated) dripper $\left(\mathrm{E}_{1}\right)$ accounted for $9.0 \%$, slightly clogged accounted for $10.8 \%$, generally clogged $11.7 \%$, seriously clogged $20.7 \%$ and completely clogged $47.7 \%$. The unclogged emitters of VARDIT Miniature flat PC dripper $\left(\mathrm{E}_{2}\right)$ accounted for $14.4 \%$, slightly clogged $12.6 \%$, generally clogged $14.4 \%$, seriously clogged $3.6 \%$ and completely clogged $55.0 \%$. The unclogged emitters of Netafim flat PC dripper $\left(\mathrm{E}_{3}\right)$ accounted for $18.0 \%$, slightly clogged accounted for $10.8 \%$, generally clogged $18.0 \%$, seriously clogged $3.6 \%$ and completely clogged $49.5 \%$. The unclogged emitters of Online PC dripper $\left(\mathrm{E}_{4}\right)$ accounted for $16.2 \%$, slightly clogged accounted for $5.4 \%$, generally clogged $8.1 \%$, seriously clogged $18.9 \%$ and completely clogged $50.5 \%$. The unclogged emitters of cusp-shaped saw-tooth $\left(\mathrm{E}_{5}\right)$ accounted for $13.5 \%$, slightly clogged $7.2 \%$, generally clogged $16.2 \%$, seriously clogged $13.5 \%$ and completely clogged $49.5 \%$. The unclogged emitters of rectangular straight-tooth $\left(\mathrm{E}_{6}\right)$ accounted for $1.8 \%$, slightly clogged $2.7 \%$, generally clogged $8.1 \%$, seriously clogged $20.7 \%$ and completely clogged $66.7 \%$. The unclogged emitters of arc-shaped saw-tooth $\left(\mathrm{E}_{7}\right)$ accounted for $1.8 \%$, slightly clogged $0.9 \%$, generally clogged $5.4 \%$, seriously clogged $25.2 \%$ and completely clogged $66.7 \%$. The unclogged emitters of arc-angular straight-tooth $\left(\mathrm{E}_{8}\right)$ accounted for $9.0 \%$, slightly clogged 


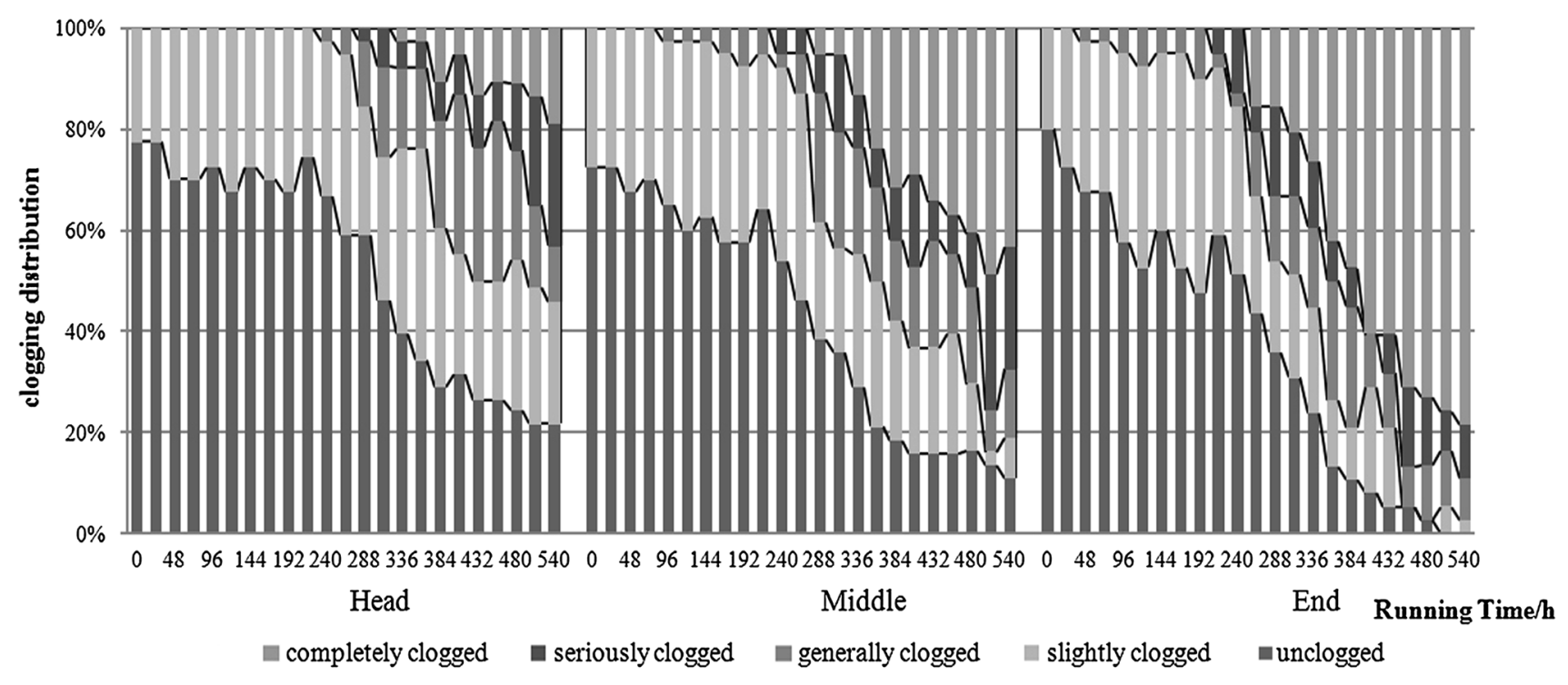

(a) $\mathrm{E}_{1}$--ADI Cylindrical PC (Pressure Compensated) dripper

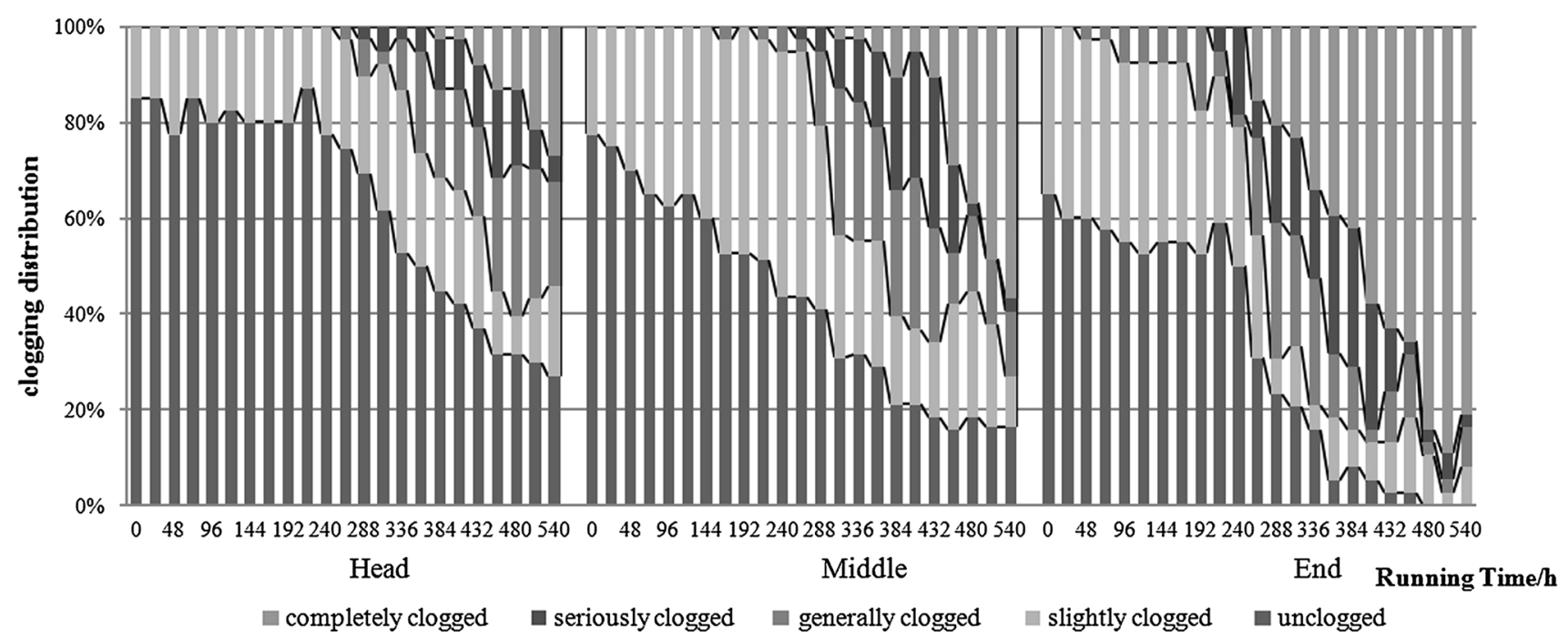

(b) $\mathrm{E}_{2}$--VARDIT Miniature flat PC dripper

Fig. 8 Dynamic changes of clogging distribution of different pressure-compensating emitters

$6.3 \%$, generally clogged $6.3 \%$, seriously clogged $23.4 \%$ and completely clogged $55.0 \%$;

Clogged emitters always firstly occurred at the end part of lateral and then moved to the middle and head parts. The head emitters clogged at last. The clogging degree always ranked as end $>$ middle $>$ head. The completely clogged emitters accounted for $18.9-40.5 \%$ at the head, while over $73.0 \%$ at the end.

In comparison, the clogging starting time was approximate between four pressure-compensating and four non-pressurecompensating emitters. However, seriously and completely clogged non-pressure-compensating emitters increased at a higher speed than the unclogged ones. The average percentage of seriously clogged emitters, completely clogged emitters, and unclogged emitters were 11.8, 50.8, $14.5 \%$, and 20.7, $59.55,6.5 \%$, respectively, in pressure-compensating and non-pressure-compensating emitters.

\section{Discussion}

The paper tested different emitters in reclaimed water drip irrigation and corrected the measured outflow data to eliminate the deviation caused by water temperature and pressure variation. The results showed that the Dra and $\mathrm{CU}$ of tested emitters varied within a fluctuated balance 


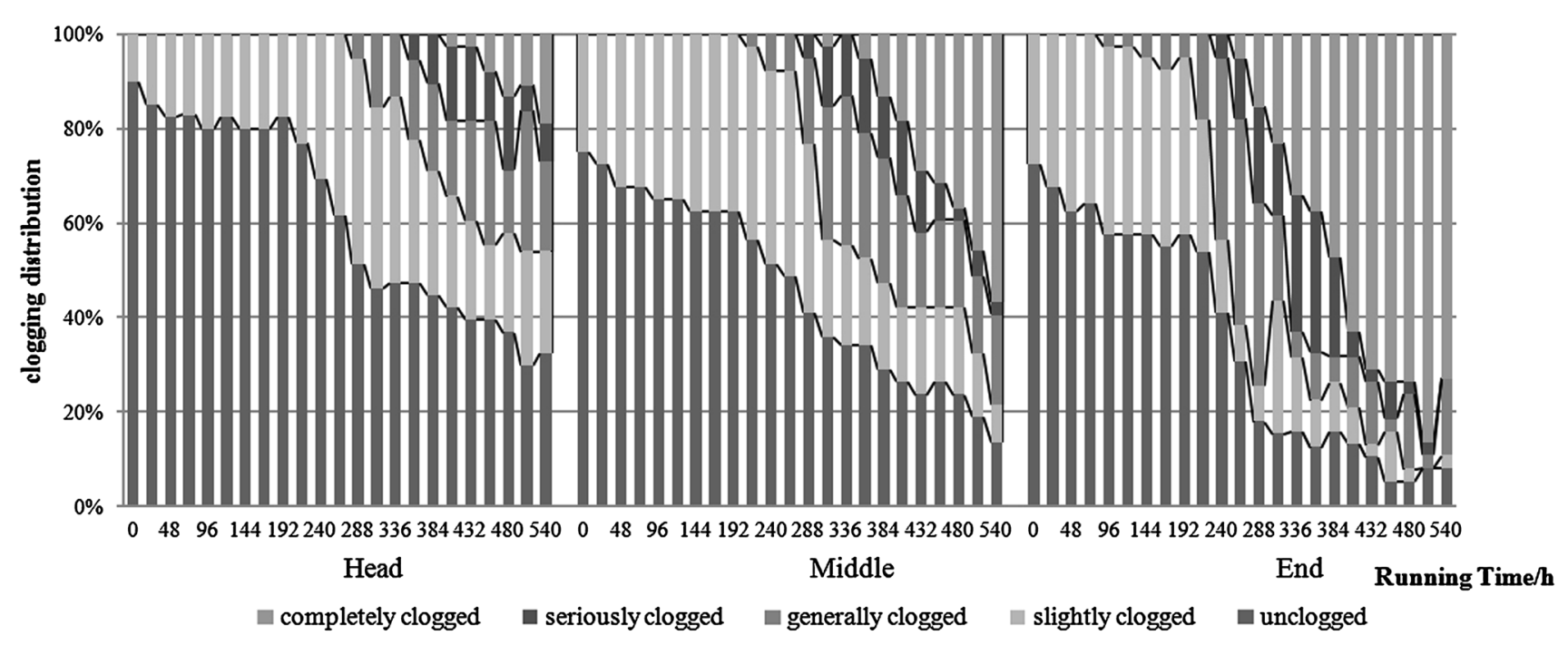

(c) $\mathrm{E}_{3}$--Netafim flat PC dripper

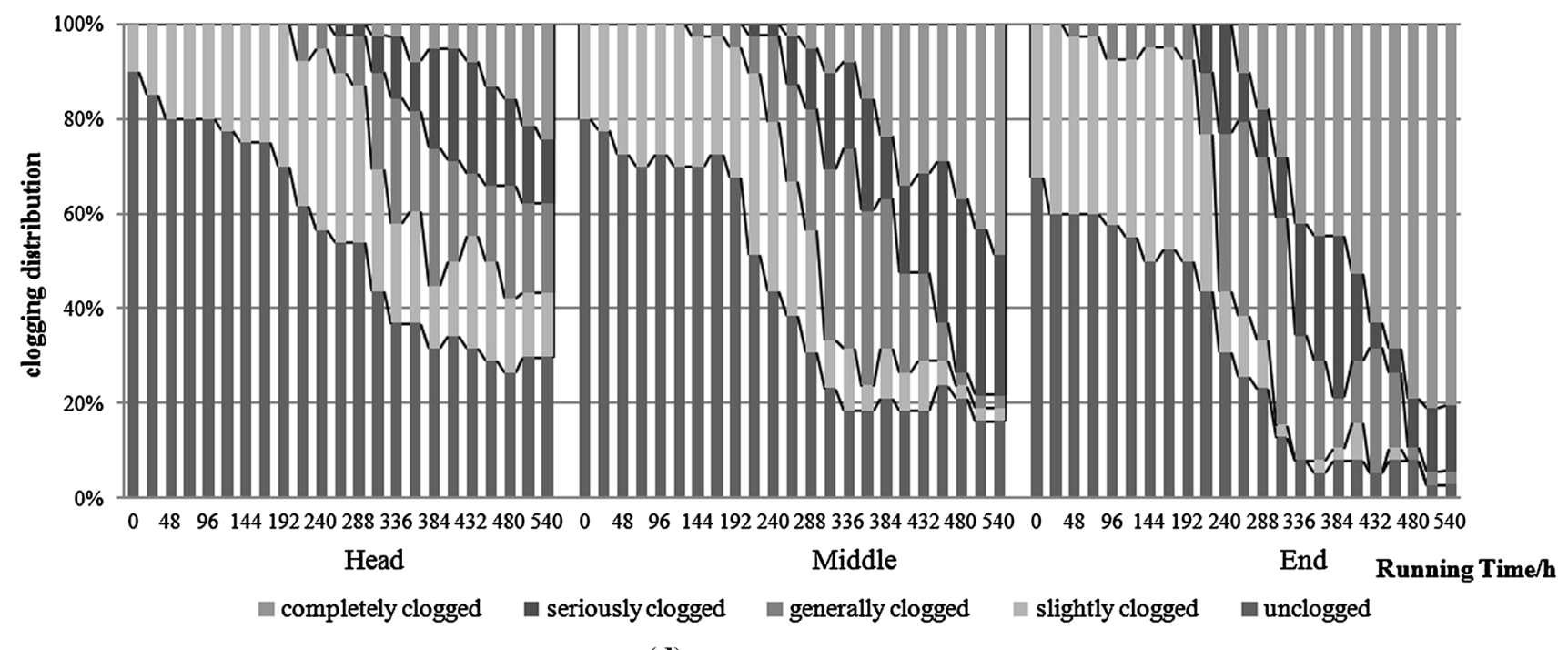

(d) $\mathrm{E}_{4}$--Online PC dripper

Fig. 8 continued

period, initial linear period and accelerated linear period with different changing properties. The fluctuated balance period came first, Dra and CU fluctuated slightly, and emitters began to clogging. Followed was the initial linear period, in which Dra and CU variation of most emitters fitted in linear well, the number of generally clogged emitters increased gradually. In the accelerated linear period after restarting in the 2 nd year, the absolute values of linear fitting gradients were larger, $R^{2}$ were above 0.91 , seriously and completely clogged emitters began to appear and increased until the end of experiment. It can be also concluded from some results that Dra varied wavy in preliminary stage and then decreased in line, but the linear characteristics were not significant and the authors did not make linear fitting (Ravina et al. 1992). The difference might come from the influence of field test and the restarting in the 2nd year, as well as the correction of measured outflow data, which eliminated the immediate effect of temperature and pressure variation. The correction was designed for making the emitter clogging status more reliable, but somehow enhanced the linear variation of Dra and CU. When the system runs to $540 \mathrm{~h}$, Dra ranged from 29.3 to $61.3 \%$, and CU from 12.7 to $41.5 \%$, which were lower than that in fresh water or ground water system at the same time span. The results proved reclaimed water would aggravate emitter clogging again (Adin and Sacks 1991; Ravina et al. 1992, 1997; Capra and Scicolone 2004; Taylor et al. 1995; Li et al. 2009). 


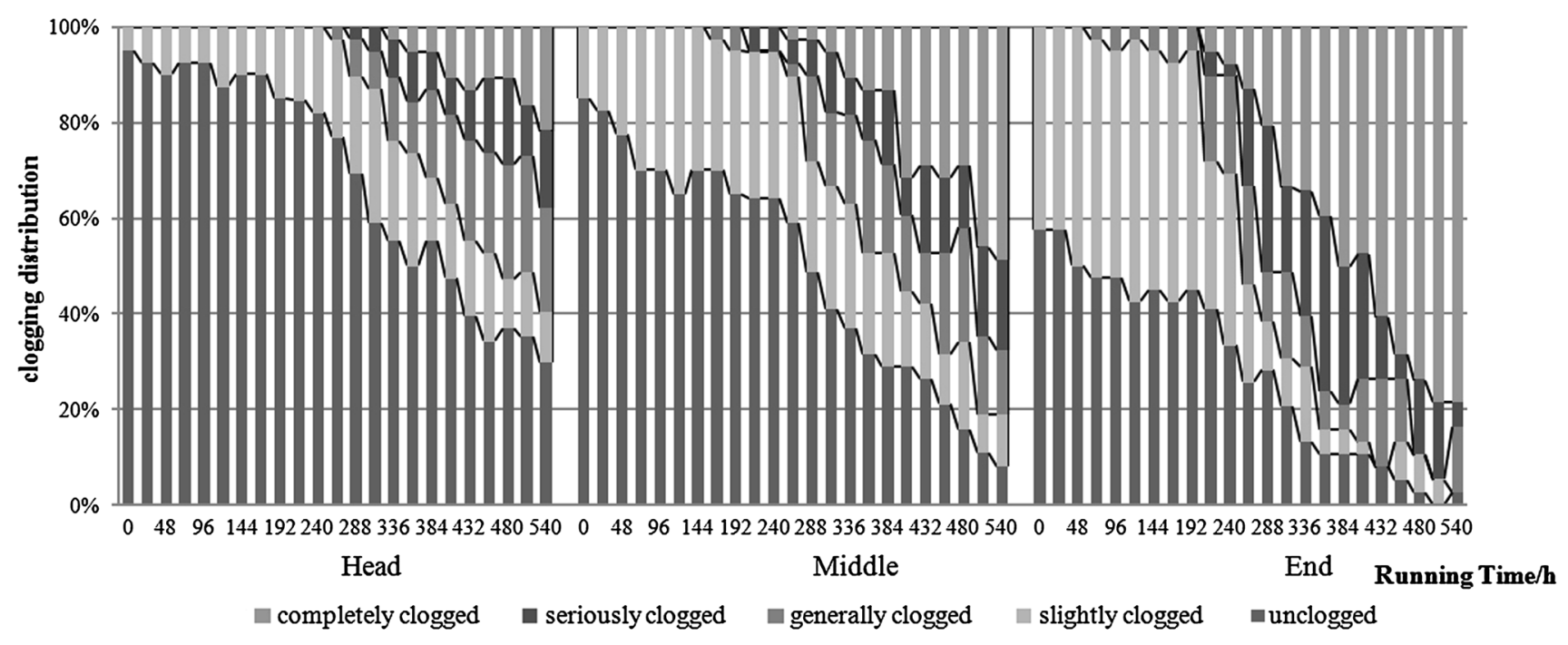

(a) $\mathrm{E}_{5}$--Cusp-shaped saw-tooth

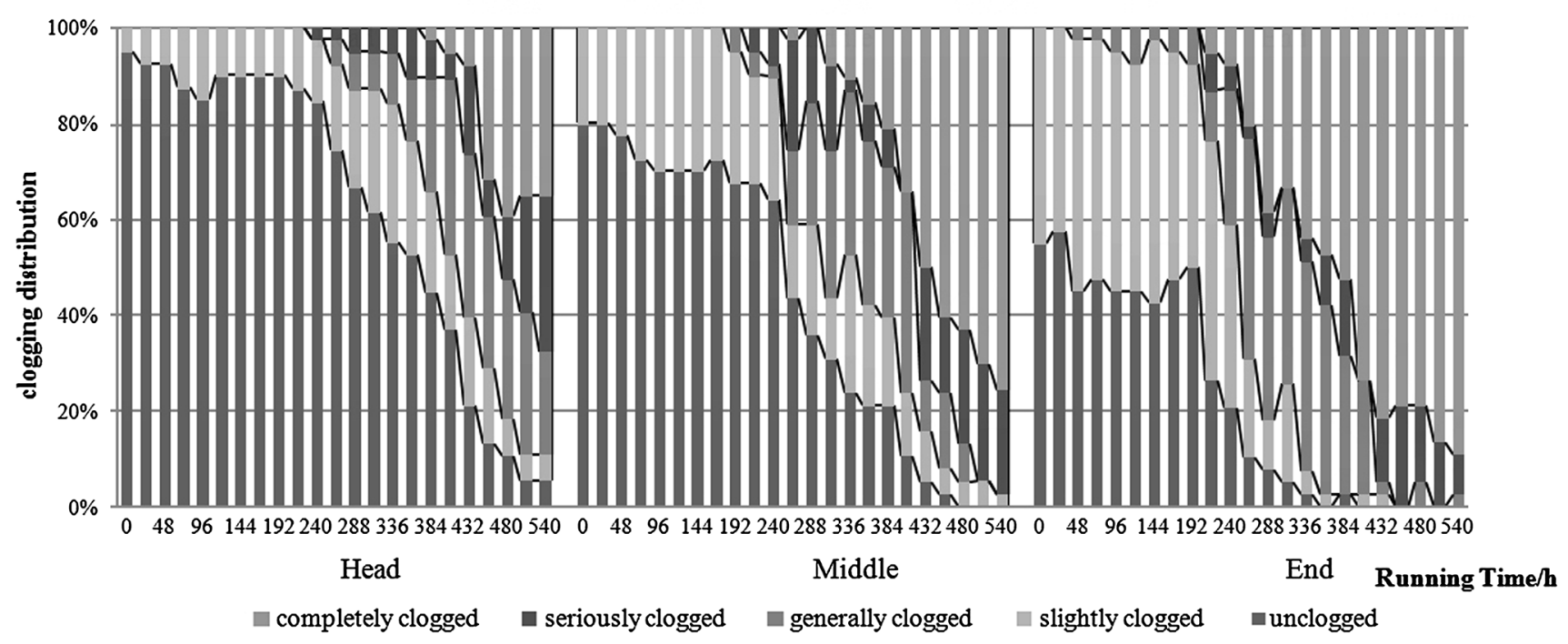

(b) $\mathrm{E}_{6}-$-Rectangular straight-tooth

Fig. 9 Dynamic changes of clogging distribution of different non-pressure-compensating emitters $\left(\mathrm{E}_{5}-\mathrm{E}_{8}\right)$

In addition, as shown in Fig. 10, Dra and CU had obvious linear relationship. The relationship between Dra and $\mathrm{CU}$ of pressure-compensating emitters was more concentrated than non-pressure-compensating ones. Pressure-compensating emitters' CU dropped when Dra decreased to about $95 \%$ and showed a linear relationship with Dra. In comparison with the other group, pressurecompensating emitters had a longer fluctuated period and smaller $R^{2}$, indicating that pressure-compensating emitters' $\mathrm{CU}$ was less sensitive than Dra. Among all the emitters, $\mathrm{E}_{3}$ and $E_{5}$ had poor linear relationship when the experiment ended. They also had larger Dra than the others.

Clogged emitters were all occurred as generally clogging emitters when the total time reached $36-48 \mathrm{~h}$. Seriously and completely clogging emitters appeared sequentially at
216-252 $\mathrm{h}$ and 252-264 h, respectively, after restarting in the 2nd year. The result was different with Capra and Scicolone (2004), in whose experiment the completely clogging emitter appeared in $5 \mathrm{~h}$ and $\mathrm{Li}$ et al. (2009) that completely clogging emitter appeared after $804 \mathrm{~h}$. The main reason was the water quality, as the suspended particles were $5-25 \mathrm{mg} / \mathrm{L}$ in the water used in the experiment. The dimension was just between those in the water used by Capra and Scicolone (2004) and Liu and Huang (2009). But the difference was relatively small with Liu and Huang (2009), because restarting the system in the 2nd year advanced the emerging time of completely clogging emitters. Completely clogging emitters increased rapidly after appearing and fluctuating slightly in the process. There were some researchers found that a few completely clogging emitters sometimes recovered high outflow (Adin 


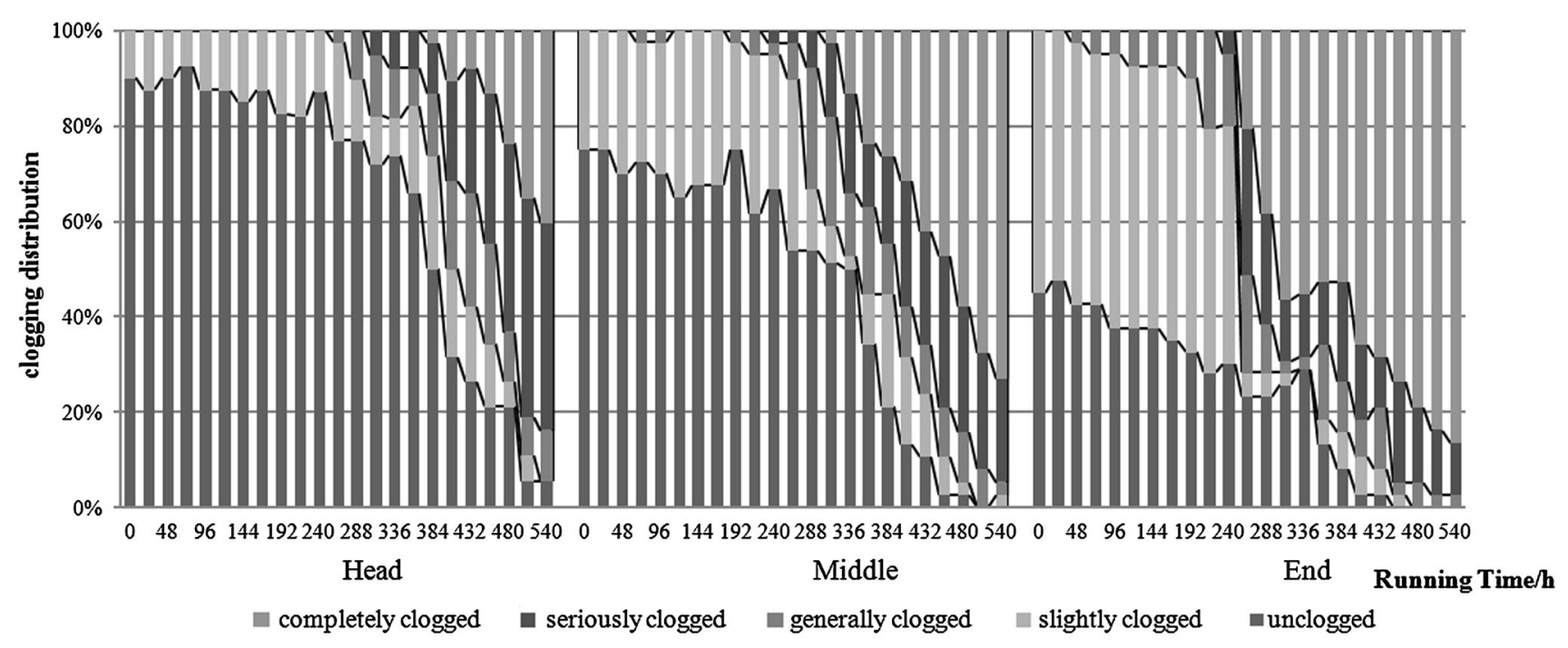

(c) $\mathrm{E}_{7}$--Arc-shaped saw-tooth

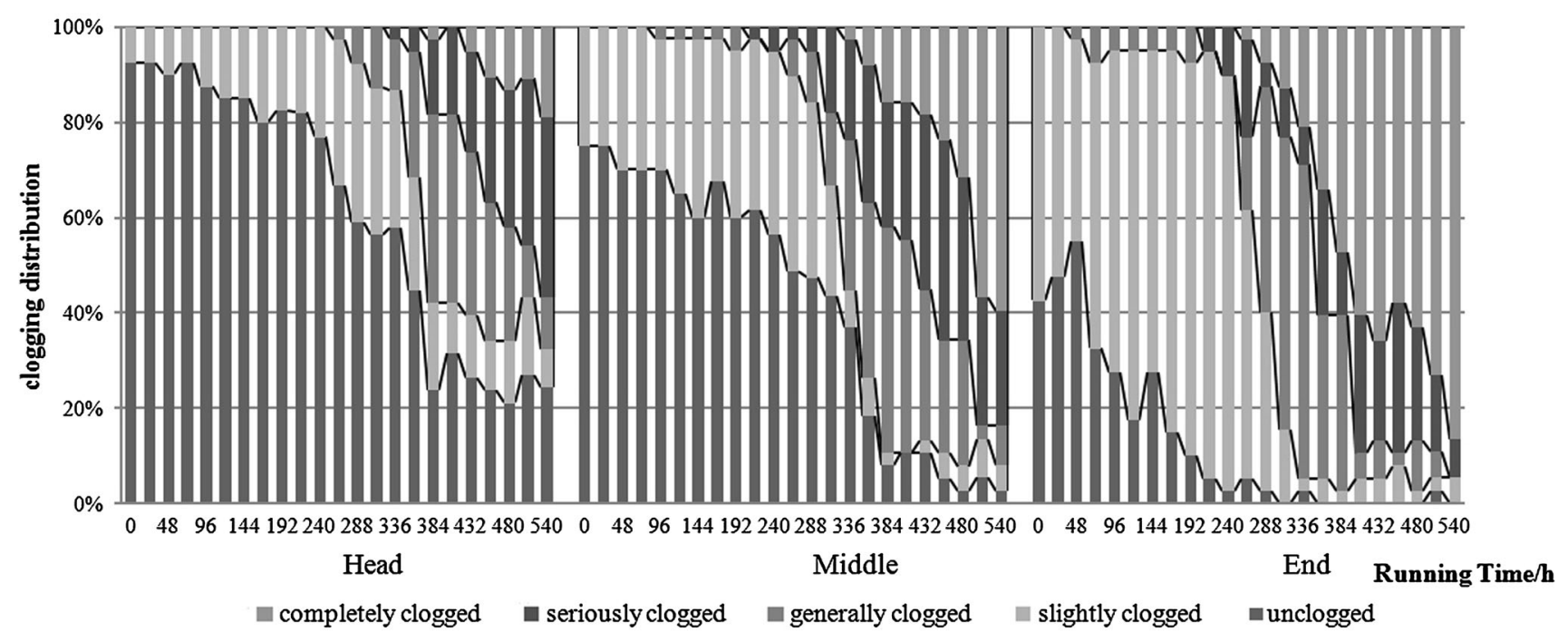

(d) $\mathrm{E}_{8}$--Arc-angular straight-tooth

Fig. 9 continued

and Sacks 1991; Duran-Ros et al. 2009), which appeared in the experiment as well. Completely clogging emitters accounted for more than $45 \%$ at the end of the experiment, which differed $<25 \%$ from Puig-Bargues et al. (2005), resulting from restarting the system in the 2 nd year. But the partly clogged emitters were still in ascendant, the same with Puig-Bargues et al. (2005) and Ravina et al. (1992). When the lateral reached a certain length, there were differences on emitters clogging distribution in head, middle and end part of the lateral, caused by nutrient transportation and velocity distribution within. Ravina et al. (1992, 1997) found that the emitters in the end part would clog easily and came at first. Puig-Bargues et al. (2005) also found that emitter type and location had a significant impact on clogging, and emitters in the end part of lateral clogged easily, but the phenomenon was not obvious in
Li's experiment (Li et al. 2009). In the paper, emitters clogged firstly at the end part of the lateral in $36-48 \mathrm{~h}$. The percentage of more severe clogged emitters in the head, middle and end part ranked as head $<$ middle $<$ end through the whole experiment. The number of completely clogged emitters in the head part was far less than that in the end part, but the clogging rate transferred from the end part to the head part. Compared with Li et al. (2012b), only when emitter number and lateral length reached a certain level, it was effective to imitate the real speed and pressure of field work emitters.

Recent researchers found that emitter type had a significant influence on clogging phenomenons. Ahmed et al. (2007) found that emitters with bigger flow stance index were poor in capability of anti-clogging, while Adin and Sacks (1991) and Wu et al. (2008) found that the length of 


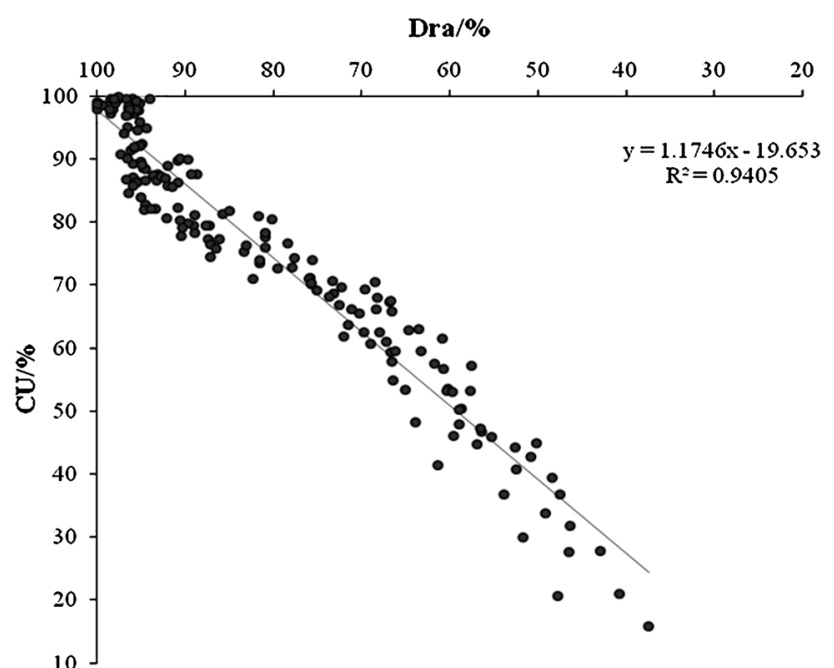

(a) Pressure-compensating emitters

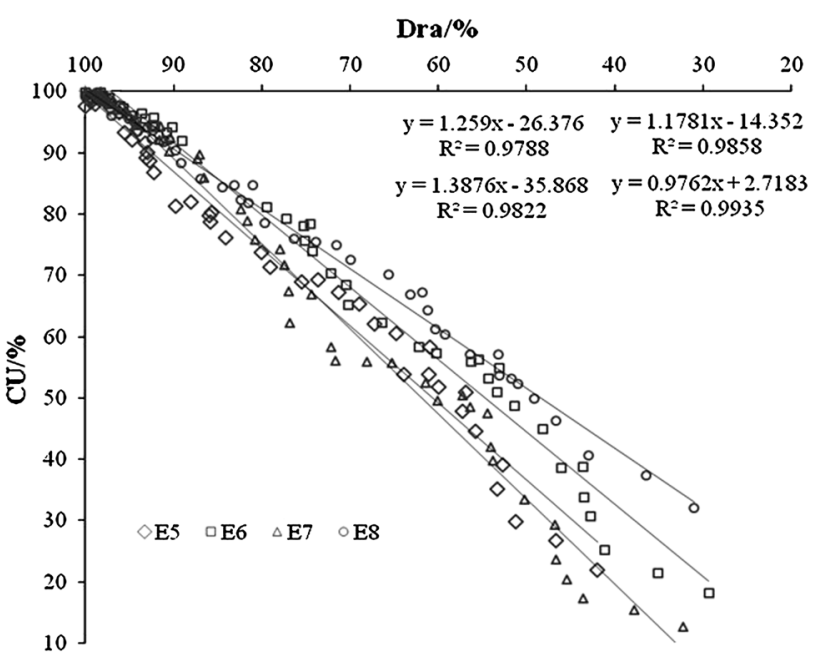

(b) Non-pressure-compensating emitters

Fig. 10 Relationship between Dra and CU

emitter flow path had a negative correlation with the suitability to reclaimed water. The pressure-compensating emitters had superiority to non-pressure-compensating emitters in the experiment, just as the same to other test (Adin and Sacks 1991; Ravina et al. 1992, 1997; Capra and Scicolone 2004; Taylor et al. 1995; Li et al. 2009; Wu et al. 2008). However, considering the economic applicability, the non-pressure-compensating emitters were more suitable in China. The influence of flow stance index on emitter clogging was not obvious in non-pressure-compensating emitters. $E_{5}$ had larger Dra in the end of experiment while $\mathrm{E}_{6}$ had the smallest, which again proved the negative relationship between emitter flow path length and suitability to reclaimed water. The flow path length had no significant effect on emitter clogging while emitter type made a big difference on $\mathrm{CU}$, indicating that type affected the development of emitter clogging. The clogging of non- pressure-compensating emitters all occurred when the system worked for $36 \mathrm{~h}$, the sensitivity of non-pressurecompensating emitters to emitter parameters was low in the preliminary stage. Furthermore, the influence of flow path length gradually increased and caused obvious differences. Moreover, flat emitters behaved better than cylindrical emitters in both pressure-compensating and non-pressurecompensating categories. Thus, when irrigates annual crop, the cusp-shaped saw-tooth non-pressure-compensating emitters with short flow path are recommend for a short period, and pressure-compensating emitters with small outflow and flow stance index were suggested for perennial crop as the irrigation equipments would use repeatedly, lateral flushing and chlorination were needed when restarting, in order to maintain a better service behavior for a long time.

In summary, we selected drip irrigation emitters using reclaimed water treated with CASS and found some preliminary results on the suitability and clogging characteristics of 8 types of emitters with the on-site experiment in the Beiqijia sewage treatment plant. These conclusions can provide a theoretical basis to clogging mechanisms and establish a more effective control mode. There still exist some issues to be solved in the future:

1. This paper was limited to the reclaimed water treated with CASS, which needs further researches on reclaimed water with other treatments;

2. It is necessary to further analyze the respective influence of outflow, flow stance index and flat, cylindrical emitters on emitter clogging;

3. It is necessary to study the influence of different hydrodynamic conditions on emitter clogging, in order to find out the relationship between those two factors and get a further understanding on clogging process.

\section{Conclusions}

Four conclusions can be drawn from the research:

1. When the temperature differences and emitters tested were sufficient, correction for measured flow could eliminate the flow deviation caused by temperature variation and the nonuniform actual work pressure after cloggings appeared. Dra and CU after correction varied in fluctuated balance period, initial linear period and accelerated linear period, and the parameters decreased in linear during the initial linear period and accelerated the reducing speed with larger gradient during the accelerated linear period. Lateral flushing, chlorination and other auxiliary measures were needed when restarting to improve the emitter clogging. 
2. Emitters started clogging within $36-48 \mathrm{~h}$, generally clogged emitters increased and Dra and CU decreased in linear when system operated for $60 \mathrm{~h}$. The differences of $\mathrm{CU}$ between emitters were significant, influenced by emitter types or flow path types. Dra dropped below $63.9 \%$ and CU dropped below $41.5 \%$.

3. The emitters in the end part clogged more easily, emitters in different clogging degrees come in incremental from head to the end part. The difference between emitter types mainly revealed in the number of unclogged and completely clogged emitters. Completely clogged emitters accounted for more than $45 \%$ when the experiment finished while unclogged emitters accounted for $<20 \%$.

4. Considering the suitability to reclaimed water drip irrigation, emitters' hydraulic performance and economic cost, the pressure-compensating flat emitters and cusp-shaped saw-tooth non-pressure-compensating emitters with short flow path were suggested in practical utilizations.

Acknowledgments We are grateful for financial support from the National Natural Science Fund of China (No. 51321001, 51339007, 51179190), New Century Excellent Researcher Award Program of Chinese Ministry of Education (NETC-10-0780) and Beijing Science and Technology Plan (D13110500070000).

\section{References}

Adin A, Sacks M (1991) Dripper clogging factor in wastewater irrigation. J Irrig Drain Eng 117(6):813-826

Ahmed BAO, Yamamoto T, Fujiyama H, Miyamoto K (2007) Assessment of emitter discharge in microirrigation system as affected by polluted water. Irrig Drain Syst 21(2):97-107

Asano T, Burton F, Leverenz H, Tsuchihashi R, Tchobanoglous G (2007) Water reuse: issues, technologies and applications. McGraw Hill Inc, New York

Bucks DA, Nakayama FS, Gilbert RG (1979) Trickle irrigation water quality and preventive maintenance. Agric Water Manag 2:149-162

Capra A, Scicolone B (2004) Emitter and filter tests for wastewater reuse by drip irrigation. Agric Water Manag 68:135-149

Chen QC, Zheng YQ (1994) The estimation of local head loss in emitters. Inner Mongolia Water Resources 4:52-54

Duran-Ros M, Puig-Bargues J, Arbat G, Barragan J, Cartagena FR (2009) Effect of filter, emitter, and location on clogging when using effluents. Agric Water Manag 96:67-79

Gilbert RG, Nakayama FS, Bucks DA, French OF, Adamson KC (1981) Trickle irrigation: emitter clogging and other flow problems. Agric Water Manag 3(3):159-178

Li YK, Yang PL, Ren SM, Yang L, Wu XB (2005) Hydraulic performance and its mechanism of liquid flow in gravity drip irrigation emitter. Transact Chin Soc Agric Mach 36(10):54-57
Li YK, Yang PL, Ren SM, Xu TW (2006) Hydraulic characterizations of tortuous flow in path drip irrigation emitter. J Hydrodyn Ser B 18(4):449-457

Li JS, Chen L, Li Y (2009) Comparison of clogging in drip emitters during application of sewage effluent and groundwater. Trans ASABE 52(4):1203-1211

Li GB, Li YK, Xu TW, Liu YZ, Jin H, Yang PL, Yan DZ, Ren SM, Tian ZF (2012a) Effects of average velocity on the growth and surface topography of biofilms attached on the reclaimed wastewater drip irrigation system laterals. Irrig Sci 30:103-113

Li JS, Li YF, Zhang H (2012b) Tomato yield and quality and emitter clogging as affected by chlorination schemes of drip irrigation systems applying sewage effluent. J Integr Agric 11(10): 1744-1754

Li YK, Liu YZ, Li GB, Xu TW, Liu HS, Ren SM, Yan DZ, Yang PL (2012c) Surface topographic characteristics of suspended particulates in reclaimed wastewater and effects on clogging in labyrinth drip irrigation emitters. Irrig Sci 30:43-56

Liu HJ, Huang GH (2009) Laboratory experiment on drip emitter clogging with fresh water and treated sewage effluent. Agric Water Manag 96:745-756

Nakayama FS, Bucks DA (1991) Water quality in drip/trickle irrigation: a review. Irrig Sci 12:187-192

Provenzano G, Pumo G (2004) Experiment analysis of local pressure losses for microirrigation laterals. J Irrig Drain Eng 130(4): 318-324

Puig-Bargues J, Arbat G, Barragan J, Cartagena FR (2005) Hydraulic performance of drip irrigation subunits using WWTP effluents. Agric Water Manag 77(1-3):249-262

Puig-Bargues J, Arbat G, Elbana M, Duran-Ross M, Barragan J, Ramire CF, Lamm FR (2010) Effect of flushing frequency on emitter clogging in microirrigation with effluents. Agric Water Manag 97(6):883-891

Ravina I, Paz E, Sofer Z, Marcu A, Shisha A, Sagi G (1992) Control of emitter clogging in drip irrigation with reclaimed water. Irrig Sci 13(3):129-139

Ravina I, Paz E, Sofer Z, Marcu A, Shisha A, Sagi G, Yechialy Z, Lev $Y$ (1997) Control of clogging in drip irrigation with stored treated municipal sewage effluent. Agric Water Manag 33(2):127-137

Scott CA, Faruqui NI, Raschid-Sally L (2004) Wastewater use in irrigated agriculture-confronting and the livelihood and environmental realities. CABI Publication, Cambridge, MA

Taylor HD, Bastos RKX, Pearson HW, Mara DD (1995) Drip irrigation with waste stabilization pond effluents: solving the problem of emitter fouling. Water Resour 29(4):1069-1078

Wu XB (2006) Experimental study on anti-clogging performance of emitters for reclaimed wastewater irrigation. China Agriculture University, Beijing

Wu XB, Wu WY, Liu HL, Hao ZY, Ma ZJ (2008) Experimental study on anti-clogging performance of emitters for reclaimed water irrigation. Trans CSAE 24(5):61-64

Yan DZ, Yang PL, Rowan M, Ren SM, Pitts D (2010) Biofilm accumulation and structure in the flow path of drip emitters using reclaimed wastewater. Trans ASABE 53(3):751-758

Yan DZ, Yang PL, Li YK, Ren SM (2011) Evaluation of drip emitter clogging with reclaimed water irrigation. Trans CSAE 27(5):19-24 